\title{
A Two-Cool-Season Wind Profiler-Based Analysis of Westward-Directed Gap Flow through the Columbia River Gorge
}

\author{
Paul J. Neiman, Daniel J. Gottas, And Allen B. White \\ NOAA/Earth System Research Laboratory/Physical Sciences Division, Boulder, Colorado
}

(Manuscript received 31 January 2019, in final form 5 September 2019)

\begin{abstract}
This observational study of westward-directed gap flows through the Columbia River Gorge uses three radar wind profilers during two winter seasons between October 2015 and April 2017, with a focus on the gapexit region at Troutdale, Oregon. Of the 92 gap-flow events identified at Troutdale, the mean duration was $38.5 \mathrm{~h}$, the mean gap-jet speed was $12 \mathrm{~m} \mathrm{~s}^{-1}$, and the mean gap-flow depth was $570 \mathrm{~m}$ MSL. The mean gap-jet height and gap-flow depth were situated below the top of the inner gorge, while a maximum depth of $1087 \mathrm{~m}$ MSL was contained within the gorge's outer-wall rim. The mean gap-flow depth was deepest in the cold-air source region east of the gorge and decreased westward to the coast. Strong gap-flow events were longer lived, deeper, and capped by stronger vertical shear than their weak counterparts, and strong (weak) events were forced primarily by a cold-interior anticyclone (offshore cyclone). Deep gap-flow events were longer lived, stronger, and had weaker capping vertical shear than shallow events, and represented a combination of gap-flow and synoptic forcing. Composite temporal analysis shows that gap-flow strength (depth) was maximized midevent (early event), freezing rain was most prevalent during the second half of the event, and accumulated precipitation was greatest late-event. Gap-flow events tended to begin (end) during the evening (morning) hours and were most persistent in January. Surface wind gusts and snow occurrences around Portland, Oregon, were associated primarily with the deepest gap flows, whereas freezing rain occurred predominantly during shallow gap flows.
\end{abstract}

\section{Introduction}

The Columbia River Gorge (CRG) is the largest and lowest cross-barrier passage in the Cascade Mountains of Oregon and Washington (Fig. 1), and it is the most prominent location in the region where coastal and continental air masses are channeled through the mountainous terrain as gap flows (e.g., Sharp 2002; Sharp and Mass 2004; Green et al. 2008; Neiman et al. 2018). The CRG is generally $<10 \mathrm{~km}$ wide below $\sim 700 \mathrm{~m}$ MSL and increases in width to $\sim 80 \mathrm{~km}$ in the layer between 700 and $2000 \mathrm{~m}$ MSL. During the cool season, low pressure dominates offshore and high pressure dominates inland, resulting in the westward extrusion (i.e., easterly gap flow) of cold continental air through the gorge into the normally maritime environment of the populous Portland, Oregon, metropolitan area. Cool-season easterly gap-flow conditions can produce damaging winds in the western gorge and around Portland. Also, reliable winds funneling through the gorge (both westbound and

\footnotetext{
Corresponding author: Paul J. Neiman, Paul.J.Neiman@ noaa.gov
}

eastbound) make this region ideal for wind energy production (e.g., Wilczak et al. 2019). Easterly gap-flow conditions can also result in snow and freezing rain, as the shallow easterlies undercut moist onshore flow associated with landfalling extratropical cyclones from the Pacific. Adverse impacts on transportation and other societal sectors often ensue.

Previous detailed observational studies of gap flows have revealed complex three-dimensional structures that can evolve rapidly between the gap entrance and exit regions (Mayr et al. 2004; Colle and Mass 2000). In general, deeper and slower flow upstream of the gap accelerates and becomes increasingly shallower across the gap, which culminates in the gap-exit region, where the maximum wind speeds and shallowest depths are observed. Model-simulation studies have shown that both synoptic-scale and mesoscale forcing control these flow behaviors, which include terrain-induced mesoscale effects such as mountain waves, upstream blocking, lee troughing, and surface friction (Gaberšek and Durran 2006; Sharp 2005). For observational measurements to capture these complex flow characteristics adequately, frequent $(<3 \mathrm{~h})$ sampling of the vertical structure of 

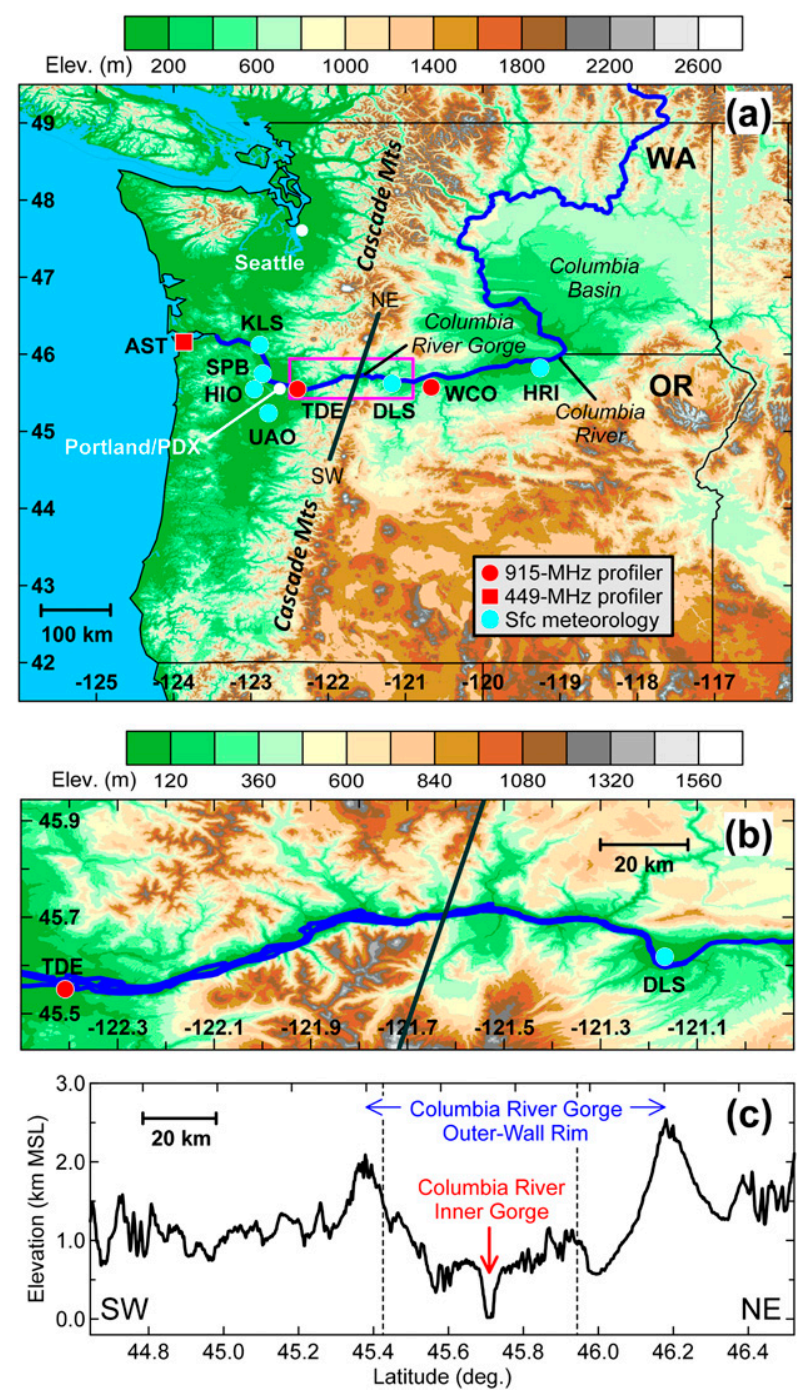

FIG. 1. (a) Terrain base map ( $\mathrm{m}$; see color scale above) of Oregon and Washington, showing the locations of the observing sites used in this study: $915-\mathrm{MHz}$ wind profilers at TDE and WCO (red circles), a $449-\mathrm{MHz}$ wind profiler at AST (red square), and surface instrumentation at KLS, SPB, HIO, UAO, DLS, HRI (blue circles), and at PDX (white circle). Surface instruments were also stationed at the wind profiler sites. The Columbia River is marked with a blue line. The pink inset box shows the domain of the zoomed in base map of the Columbia River Gorge region in (b). The dark line NE-SW is a projection for the cross section in (c). (b) Zoomed in terrain base map ( $\mathrm{m}$, see color scale above) of the Columbia River Gorge region. The dark line represents the segment of the cross-sectional projection cutting through the domain. (c) Terrain cross section across the Columbia River Gorge along line NE-SW in (a). The vertical dashed lines denote the north and south boundaries in (b).

wind and temperature has been deemed essential at locations both upstream and downstream of the gap (Mayr et al. 2007). Remote sensors, including radar, lidar, and sodar offer potential to fulfill these sampling requirements and have been used to study the vertical structure of gap-flows in the Birch Creek Valley of Idaho (Finn et al. 2016), the Wipp Valley of Austria (Mayr et al. 2007), the Gastineau Channel of Alaska (Bond et al. 2006), and the Petaluma Gap of California (Neiman et al. 2006). For the observational study of gap flows in the CRG, a radar wind profiler is likely the optimal remote sensor for the following two reasons. First, data-retrieval limitations in weak signal backscattering environments, such as dry continental air within gap flows, are less of an issue when the gap-flow depth is within close range of the radar, as is typically observed in the CRG (e.g., $<1.25 \mathrm{~km}$ MSL). Second, since precipitation occurs frequently in the CRG, as moist Pacific airstreams overrun the gap flow, signal attenuation prevents data retrieval for both lidar and sodar, whereas ultrahigh-frequency (UHF) radar wind profiler signals are enhanced by precipitation (McDonald et al. 2004) and time-height data coverage is maximized.

Objective analysis of the vertically observed kinematic structure is an effective method for monitoring and studying the complex spatiotemporal characteristics of gap flow. Neiman et al. (2018) established wind speed and directional shear criteria to detect gap flow jet speed and depth for CRG gap flow using individual hourly averaged wind profiles. In this application, these gap flow metrics were used to develop a real-time, webbased, gap-flow detection product that provides situational awareness to forecasters in the National Oceanic and Atmospheric Administration (NOAA) National Weather Service (NWS) Portland Forecast Office. In the new study presented below, these same metrics are utilized to document and study the gap-flow characteristics along the CRG and assess the related meteorological impacts downstream across the Portland metropolitan area.

A thorough literature review of gap flows, both generally and specific to the CRG, is provided in the research-centric contribution by Sharp and Mass (2004) and in the operationally focused study by Neiman et al. (2018). The Sharp and Mass (2004) contribution is the most comprehensive research-oriented observational study to date focusing on cool-season easterly gap flows through the CRG, synoptic controls on these gap flows, and the regional weather and climate impacts of these flows. Although Sharp (2002) and Sharp and Mass (2004) significantly expanded understanding of coolseason gap flows exiting the CRG toward Portland, their observing platforms were limited primarily to monitoring surface conditions, although Sharp (2002) also presented several instantaneous snapshots of gapflow vertical structure using commercial aircraft and operational radar data. 
The present study complements surface observations with unique temporally continuous upper-air data gathered by radar wind profilers during the cool seasons of October 2015-April 2016 and October 2016-April 2017. This dataset provides a comprehensive observational characterization of the composite vertical and temporal structure of gap flows along the Columbia River from the interior basin to the coast, with an emphasis on the exit region of the gorge. Composite wind profiler-based observational metrics of gap flows in the exit region of the CRG-which have not been documented previously in the literature-include the depth of the gap flow and the strength of its jet. We use these metrics to establish their diagnostic relationships with surface wind speed and winter precipitation-type impacts (i.e., snow and freezing rain; rare occurrences of ice pellets excluded) downstream across the Portland metropolitan area. These metrics are also compared to the same metrics generated from an operational rapidrefresh numerical weather prediction model in order to demonstrate a potential application of the gap flow metrics in evaluating model performance.

\section{Observing systems and gridded datasets}

A suite of research instruments was installed in the CRG and Columbia basin of eastern Oregon and Washington in the fall of 2015 for the second Wind Forecast Improvement Project (WFIP2; Wilczak et al. 2019), an 18-month campaign funded by the U.S. Department of Energy (DOE) and NOAA. Our study utilizes data collected from two key instruments deployed during WFIP2: a NOAA/Earth System Research Laboratory (ESRL) 915-MHz wind profiler at the west end of the CRG at Troutdale, Oregon (TDE) and a second NOAA/ESRL $915-\mathrm{MHz}$ wind profiler in the Columbia basin at Wasco, Oregon (WCO) (Fig. 1, Table 1). Additional instruments used in this study include a $449-\mathrm{MHz}$ wind profiler operated by DOE's Pacific Northwest National Laboratory (PNNL) at the mouth of the Columbia River near Astoria, Oregon (AST), and operational surface meteorology sites along or near the Columbia River at AST; Kelso-Longview, Washington (KLS); Scappoose, OR (SPB); Hillsboro, OR (HIO); Aurora, OR (UAO); PDX; TDE (located $15 \mathrm{~km}$ east-southeast of PDX); The Dalles, OR (DLS); and Hermiston, OR (HRI) (Fig. 1, Table 1). These and additional observing platforms are described below.

The 915-MHz wind profilers (e.g., Carter et al. 1995) collected hourly averaged profiles of horizontal wind in high- and low-resolution modes, although we used only the high-resolution mode. Each hourly time stamp is valid at the beginning of the averaging period, and wind profiles displayed in time-height sections are plotted at the middle of the hour. At TDE, the high-mode profiles extended from 150 to $2523 \mathrm{~m}$ MSL with 58-m range-gate spacing. The high-mode profiles at WCO spanned an altitude range of 543-3004 m MSL, also with 58-m resolution. A radio acoustic sounding system (RASS; Martner et al. 1993) accompanied the wind profiler at TDE. The RASS provided hourly profiles of virtual temperature between 150 and $1701 \mathrm{~m}$ MSL every $60 \mathrm{~m}$, and they were converted to virtual potential temperature profiles by integrating the hypsometric equation using the surface pressure as a lower boundary and RASS layer-mean virtual temperatures. Gap-flow events with strong winds reduce the RASS vertical coverage to within a couple hundred meters above the radar, thus precluding the opportunity to use RASS in the forthcoming composite analyses. As with the $915-\mathrm{MHz}$ systems, the $449-\mathrm{MHz}$ wind profiler (White et al. 2013) collected data in two modes, with only the high-resolution mode used: 197-5061 m MSL at $101 \mathrm{~m}$ intervals.

At each wind profiler site, instruments affixed to a 10-m tower collected the following surface observations every $2 \mathrm{~min}$ : pressure, temperature, and relative humidity at $2 \mathrm{~m}$ above ground level (AGL) and wind velocity at $10 \mathrm{~m}$ AGL. A heated tipping-bucket gauge adjacent to the tower measured precipitation at 2-min intervals. These data were averaged into 1-h blocks. Elsewhere, operational sites at KLS, SPB, PDX, HIO, UAO, DLS, and HRI collected hourly surface pressure, temperature, relative humidity, and wind velocity, as did two additional operational sites at AST and TDE (which are collocated with those wind profilers). Hourly operational reports of precipitation type were provided at TDE, PDX, HIO, UAO, and SPB.

To provide synoptic-scale context for the observational analyses, we utilized the Climate Forecast System Reanalysis (CFSR; Saha et al. 2010) that is available between 1979 and 2011, and the newer, upgraded Climate Forecast System, version 2, operational analysis (CFSv2; Saha et al. 2014) available since 2011. These gridded datasets were developed by NOAA's National Centers for Environmental Prediction (NCEP) and are now maintained by the National Centers for Environmental Information (NCEI). We downloaded these 6-h data from NOAA/NCEI's Operational Model Archive and Distribution System (NOMADS) at $0.5^{\circ} \times 0.5^{\circ}$ latitude-longitude resolution and with 64 vertical levels.

\section{Composite analysis across two consecutive cool seasons}

In this section, we employ composite analysis techniques for the 2015-16 and 2016-17 cool seasons to 
TABLE 1. Site information for key observing platforms.

\begin{tabular}{|c|c|c|c|c|c|c|}
\hline Location & 3-letter name & Lat $\left({ }^{\circ} \mathrm{N}\right)$ & Lon $\left({ }^{\circ} \mathrm{W}\right)$ & $\begin{array}{l}\text { Elevation } \\
\text { (m MSL) }\end{array}$ & Observing platforms & Agency \\
\hline Astoria, OR & AST & 46.157 & 123.883 & 3 & $\begin{array}{l}\text { 449-MHz wind profiler } \\
\text { surface meteorology }\end{array}$ & $\begin{array}{l}\text { U.S. DOE/PNNL, } \\
\text { NOAA/NWS }\end{array}$ \\
\hline Troutdale, OR & TDE & 45.554 & 122.386 & 12 & $\begin{array}{l}\text { 915-MHz wind profiler } \\
\text { RASS disdrometer } \\
\text { surface meteorology }\end{array}$ & $\begin{array}{l}\text { NOAA/Earth System } \\
\text { Research Laboratory } \\
\text { and NOAA/NWS }\end{array}$ \\
\hline Portland, OR & PDX & 45.596 & 122.609 & 6 & Surface meteorology & NOAA/NWS \\
\hline Wasco, OR & WCO & 45.590 & 120.672 & 462 & $\begin{array}{l}\text { 915-MHz wind profiler } \\
\text { surface meteorology }\end{array}$ & $\begin{array}{l}\text { NOAA/Earth System } \\
\text { Research Laboratory }\end{array}$ \\
\hline Kelso-Longview, $\mathrm{WA}^{\mathrm{a}}$ & KLS & 46.117 & 122.894 & 6 & Surface meteorology & NOAA/NWS \\
\hline Longview, $\mathrm{WA}^{\mathrm{b}}$ & LOP & 46.100 & 122.950 & 3 & Surface meteorology & NOAA/NWS \\
\hline Scappoose, OR & SPB & 45.769 & 122.864 & 17 & Surface meteorology & NOAA/NWS \\
\hline Hillsboro, OR & $\mathrm{HIO}$ & 45.548 & 122.956 & 62 & Surface meteorology & NOAA/NWS \\
\hline Aurora, OR & UAO & 45.247 & 122.771 & 60 & Surface meteorology & NOAA/NWS \\
\hline The Dalles, OR & DLS & 45.619 & 121.166 & 72 & Surface meteorology & NOAA/NWS \\
\hline Hermiston, OR & HRI & 45.826 & 119.261 & 195 & Surface meteorology & NOAA/NWS \\
\hline
\end{tabular}

${ }^{\text {a }}$ NWS is the National Weather Service.

${ }^{\mathrm{b}}$ At Longview, the sea level pressure at the river site (LOP) was combined with the other surface meteorological variables measured at the airport (KLS), since the pressure sensor at the airport was not working. The combined dataset is referred to as KLS in the body of the paper. Reliable precipitation gauge measurements were not available from either site.

showcase spatiotemporal structural characteristics of gapflow events observed along the Columbia River corridor from the interior Columbia basin, through the gorge, and westward to the Pacific coast. But before presenting the composite analyses, it is instructive to first examine the vertical-temporal structure and the synoptic environment of a well-defined gap-flow case observed at TDE (Fig. 2). Shallow easterly gap flow persisted for $28 \mathrm{~h}$ between 0000 UTC 17 December and 0400 UTC 18 December 2015. The gap-flow depth, ascertained hourly using an automated algorithm (Neiman et al. 2018 ), was $\sim 400 \mathrm{~m} \mathrm{MSL}$ at the start of the event, increased to $\sim 800 \mathrm{~m}$ during midevent, and decreased to $\sim 250 \mathrm{~m}$ by the event's conclusion. The magnitude of the gap flow increased to a maximum value of $\sim 20 \mathrm{~m} \mathrm{~s}^{-1}$ in a jet-like configuration centered at $500 \mathrm{~m}$ MSL during the midpoint of the event, when the lowlevel temperature gradient was enhanced by arctic air over the interior and warm maritime air along the coast in association with an amplified synoptic wave train (Figs. 2c,d). The gap flow strengthened and deepened in conjunction with intensifying maritime south-tosouthwesterly flow aloft, as an extratropical cyclone approached the coast (inferred from Figs. 2c,d), and subsequently weakened, eroded, and terminated with the temporal descent of the strong southwesterly airstream toward the surface. Companion RASS observations highlight the cold continental character of the shallow gap flow and the subsequent temporal descent of warmer air toward the surface within the maritime southwesterlies.

\section{a. Vertical and plan-view perspectives}

\section{1) Full 92-CASE WIND PROFILER COMPOSITE RESULTS}

To generate composite analyses of gap-flow events, we developed a catalog of events using the observational spectrum of surface and radar wind data at TDE to adapt the event-detection methodology in Neiman et al. (2006) to the CRG. To be labeled as a gap-flow event, the following criteria must be met for six consecutive hours at TDE: 1 ) surface wind direction of $55^{\circ}-112^{\circ}$, 2) frictionally rotated layer-mean wind direction of $65^{\circ}-130^{\circ}$ between 100 and $350 \mathrm{~m}$ MSL (i.e., in the four lowest wind profiler range gates), and 3) easterly component of $\geq 5 \mathrm{~m} \mathrm{~s}^{-1}$ in the same 100-350 $\mathrm{m}$ layer. Of note, the broad wind direction range in the $100-350 \mathrm{~m}$ MSL layer is needed to capture backing or veering wind profiles, while surface-wind speed criteria are excluded due to the frequent flowdecoupling influences of local drainage flows from the Sandy River located southeast of TDE. Collectively, the average wind direction of $90^{\circ}$ corresponds to the CRG orientation. Between 28 September 2015 and 30 June 2017, 100 gap-flow events were observed exiting the CRG. For the cool-season period OctoberApril, when cold air in the interior and precipitation are most likely, 92 cases spanning $3546 \mathrm{~h}$ were observed (Table 2), with 44 occurring during year 1 (i.e., October 2015-April 2016) and 48 during year 2 (i.e., October 2016-April 2017). 

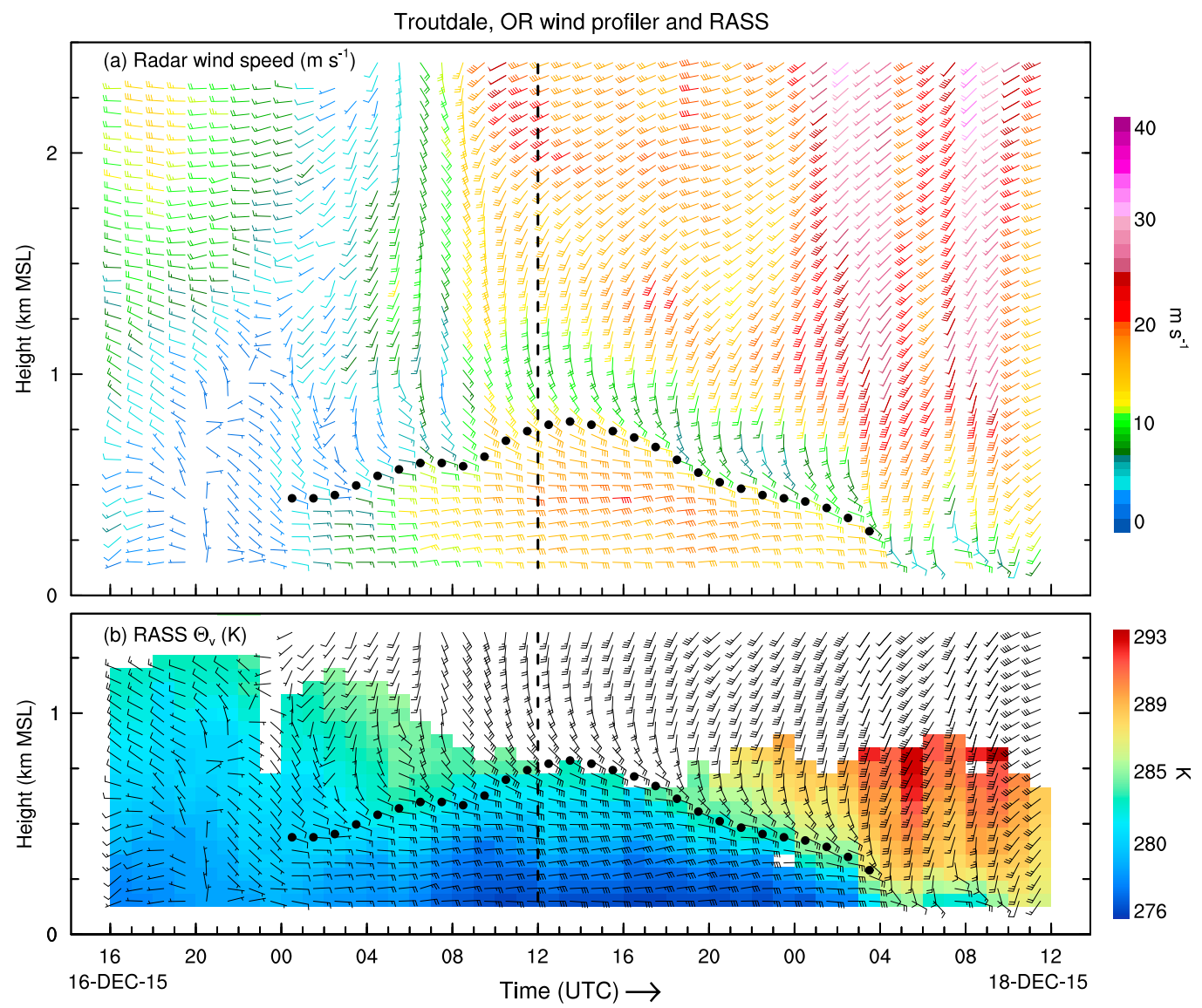

Synoptic maps - 17-DEC-15 12 UTC
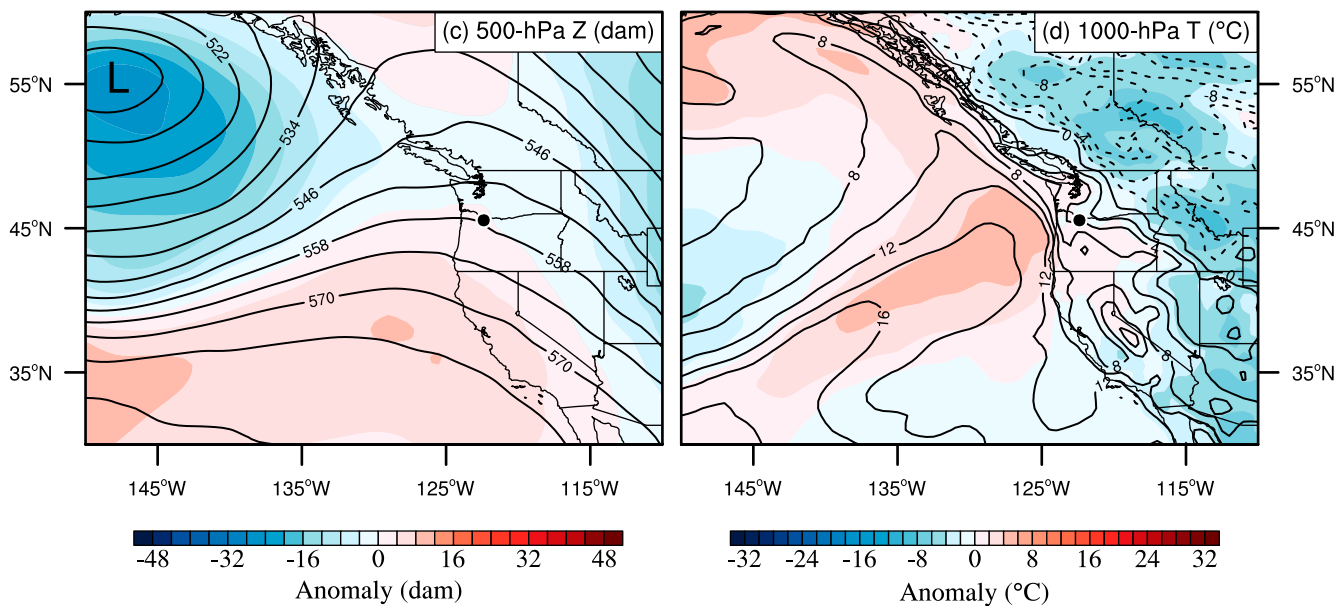

FIG. 2. Time-height sections of data from the 915-MHz wind profiler and RASS at Troutdale, Oregon (TDE), between 1600 UTC 16 Dec and 1200 UTC 18 Dec 2015, and accompanying plan-view synoptic maps at 1200 UTC 17 Dec 2015 derived from NOAA's Climate Forecast System: (a) Hourly radar wind profiles (flag: $25 \mathrm{~m} \mathrm{~s}^{-1}$; barb: $5 \mathrm{~m} \mathrm{~s}^{-1}$; half-barb: $2.5 \mathrm{~m} \mathrm{~s}^{-1}$ ) color-coded by wind speed $\left(\mathrm{m} \mathrm{s}^{-1}\right)$, and the top of the gap flow (black dots) derived from the algorithm of Neiman et al. (2018); (b) hourly color-coded profiles of RASS virtual potential temperature $\left(\theta_{v} ; \mathrm{K}\right)$, and black dots are as in (a); (c) analysis and anomaly (solid and color-filled contours, respectively) for $500-\mathrm{hPa}$ height $(\mathrm{dam})$; and $(\mathrm{d})$ as in $(\mathrm{c})$, but for $1000-\mathrm{hPa}$ temperature $\left({ }^{\circ} \mathrm{C}\right)$. The vertical black dashed lines in (a) and (b) represent the time of the analyses in (c) and (d). 


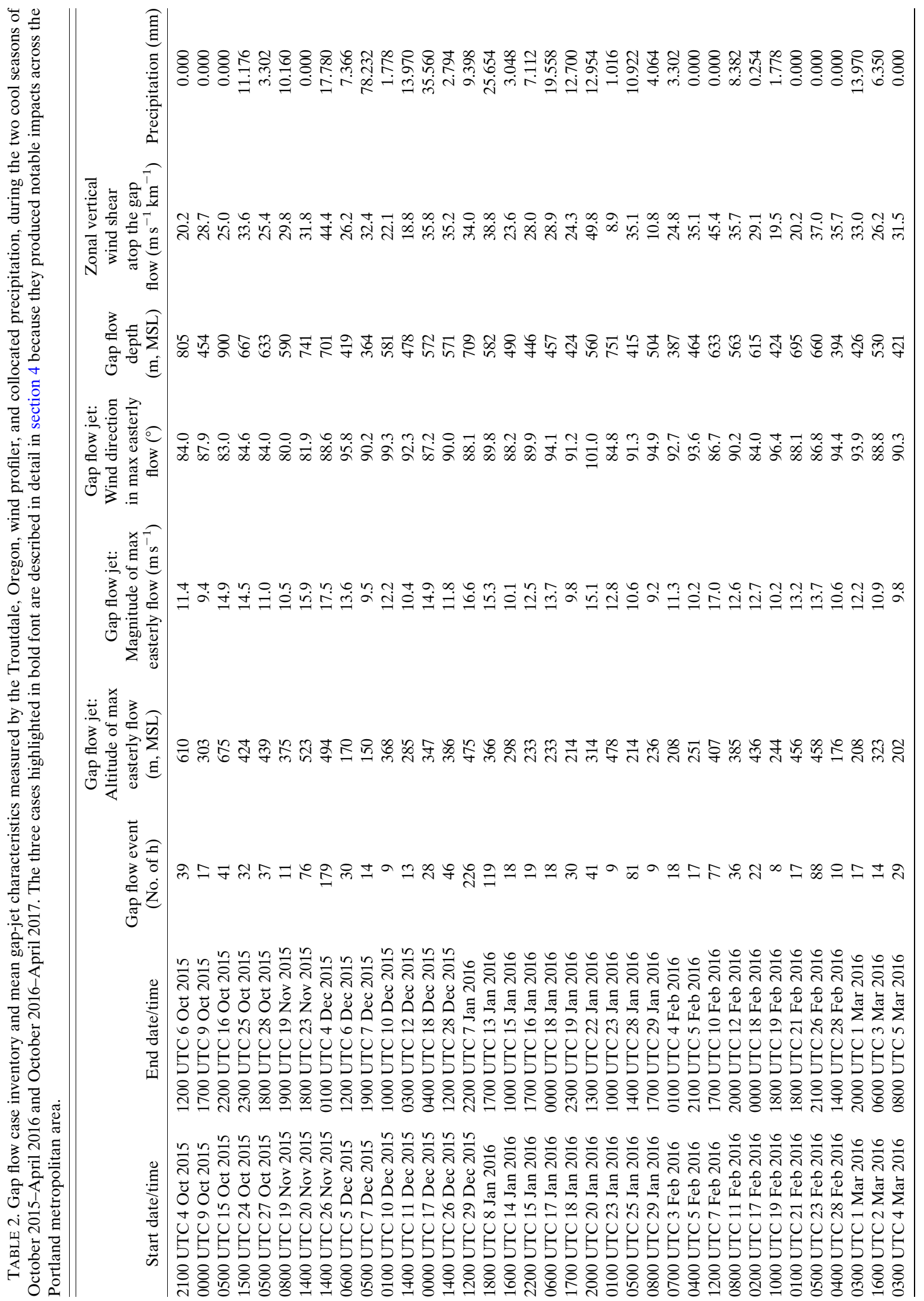




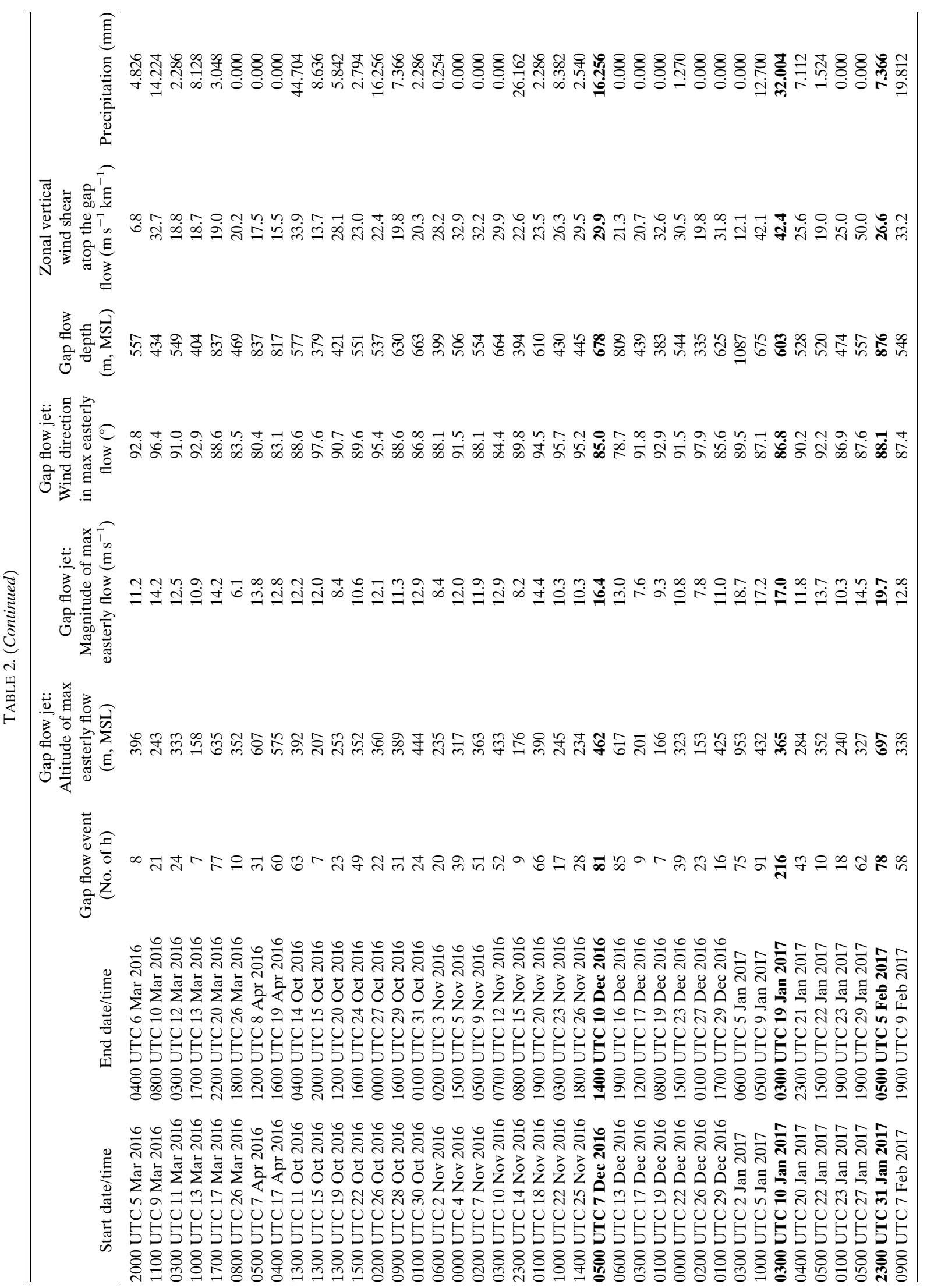




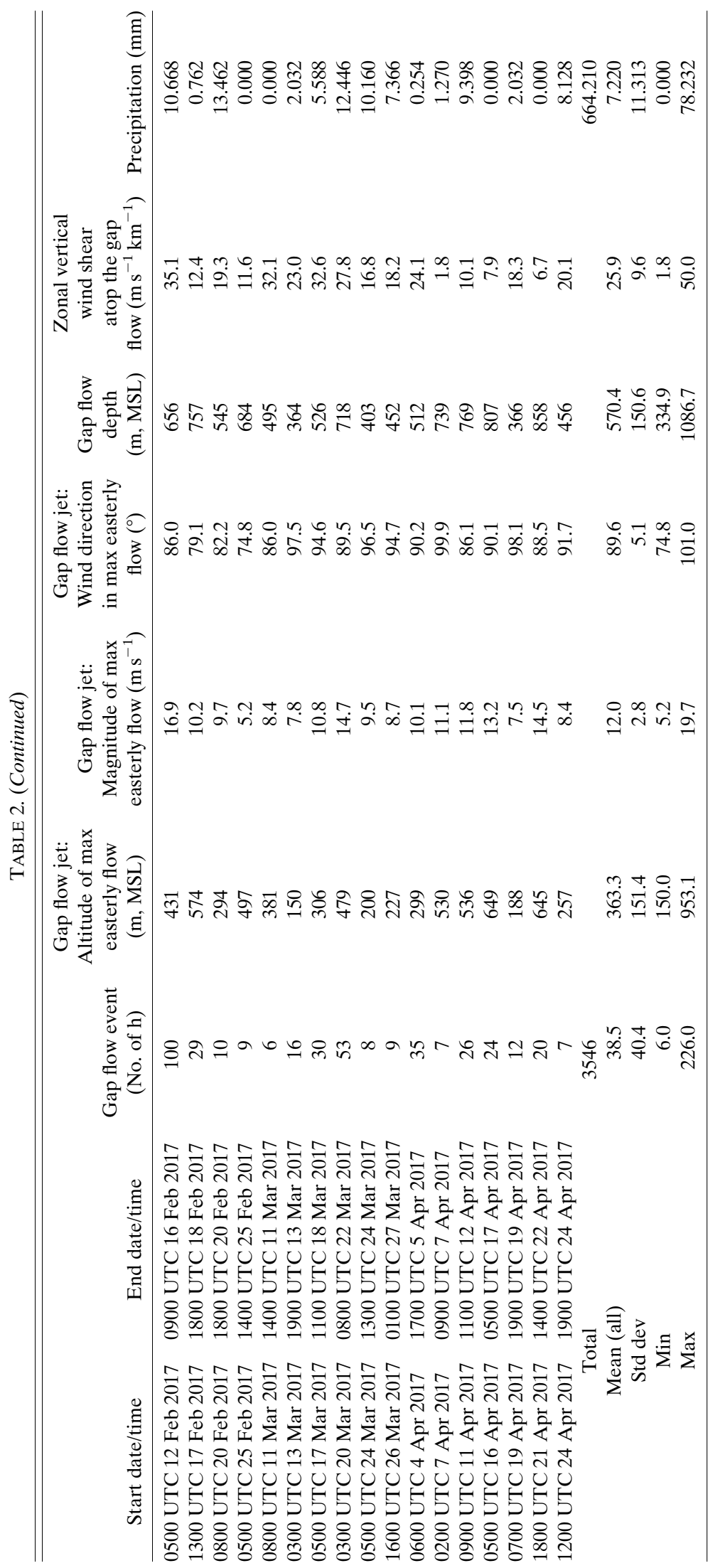


The statistical characteristics of each gap-flow case observed at TDE were determined by averaging the consecutive hourly vertical-profile metrics produced by the Neiman et al. (2018) algorithm for that case (Table 2). The statistics for the full 92-case inventory at TDE were established by averaging the mean characteristics of those 92 cases (bottom of Table 2). The cases range in duration between 6 and $226 \mathrm{~h}$, with a mean of $38.5 \mathrm{~h}$, and they account for $34.7 \%$ of the total number of hours during this two coolseason period. The mean altitude of the gap-flow jet (i.e., the altitude where the easterly flow is maximized) resides at $363 \mathrm{~m}$ MSL, with bounds of 150 and $953 \mathrm{~m}$ MSL. These values reside mostly beneath the top of the inner gorge walls at $\sim 700 \mathrm{~m} \mathrm{MSL}$ (Fig. 1c). The gap-jet mean velocity is $12 \mathrm{~m} \mathrm{~s}^{-1}$ from $89.6^{\circ}$, with case averages as weak and strong as 5.2 and $19.7 \mathrm{~m} \mathrm{~s}^{-1}$. Atop the gap jet, strong vertical wind shear marks the upper bound of the channeled flow, which was quantified for each case by averaging the hourly zonal shear across the two adjacent wind profiler range gates surrounding the altitude of the hourly gap-flow depth over the duration of the event. The mean magnitude of the capping shear layer is $25.9 \mathrm{~m} \mathrm{~s}^{-1} \mathrm{~km}^{-1}$ at the mean gap-flow-depth altitude of $570 \mathrm{~m} \mathrm{MSL}$, which also resides below the top of the inner gorge. The spread in mean gap-flow depth is considerable, ranging from 335 to $1087 \mathrm{~m} \mathrm{MSL}$, with the deepest case occurring at an altitude above (below) the gorge's inner- (outer-) wall rim. Seventy percent of gap-flow cases are associated with accumulating precipitation at TDE. The total precipitation during gap-flow events is $664 \mathrm{~mm}$, or $30 \%$ of the total observed during the two winters. Given that gap-flow events constitute $34.7 \%$ of this period, these events, collectively, are only slightly drier than average.

To evaluate the mean vertical structure of flows through and above the CRG during the 92 gap-flow events observed at TDE, all 3546 hourly wind profiles were averaged into composite profiles of wind speed and direction and their zonal and meridional components ( $U$ and $V$, respectively) up to $\sim 2.2 \mathrm{~km}$ MSL. Collocated surface data were also averaged and then included in the composite profiles. Composite wind profiles were also constructed at WCO (i.e., the gapflow source region in the Columbia basin) and AST (i.e., the mouth of the Columbia River on the Pacific coast), and composite surface values were generated at six sites from the Columbia basin to the coast, using the same hours as at TDE. For the composite profiles at WCO, which is nearly $400 \mathrm{~m}$ above the Columbia River, composite surface data from DLS also were included to depict flow along the nearby river corridor. All composite profiles described above, together with standard deviation bars, are shown in Figs. 3 and 4 (black lines), and the surface composite counterparts are presented in the first column of Figs. 5 and 6 . Although these composites are duplicated to enable subsequent comparison with both gap-flow stratifications (i.e., strength and depth), we initially refer to Figs. 3 and 5 only in our discussion of the 92-case composites.

At the mouth of the CRG at TDE (Fig. 3, middle column), a bimodal $12 \mathrm{~m} \mathrm{~s}^{-1}$ maximum in wind speed and $U$ between 0.2 and $0.5 \mathrm{~km}$ MSL define the easterly gap-flow jet. Above the jet, the flow veers to southeasterly at $1 \mathrm{~km}$ MSL and to south-southwesterly in the free troposphere above. In the Columbia basin at WCO (Fig. 3, right column), the flow is weaker than at TDE throughout the column, although the easterly flow is deeper-extending up to $1 \mathrm{~km}$ MSL before veering to ambient south-southwesterly aloft. The deeper easterlies quite likely reflect deeper cold air in the basin than in the gorge. Along the coast at AST (Fig. 3, left column), there is only weak evidence of remnant gap flow, which confirms the Sharp (2002) model simulation of the spreading and collapsing of gap flow in its exit region where shallow terrain no longer constrains the flow. Shallow southeasterly flow at and near the surface veers to southerly at $1 \mathrm{~km}$ MSL and then to ambient southsouthwesterly aloft.

The surface composites in Fig. 5 (left column) show easterly flow at the three sites in the basin and gorge (i.e., HRI, DLS, TDE), veering sharply downriver at SPB to south-southwesterly, and backing farther downriver at KLS to southeasterly and to eastsoutheasterly at the coast at AST. The directionality of the surface flow from the interior to the coast mirrors the orientation of the Columbia River, hence pointing to channeling of the surface flow by the river corridor during gap-flow conditions. The magnitude of the surface flow is weak (i.e., $<3 \mathrm{~m} \mathrm{~s}^{-1}$ ) at all sites except TDE, where stronger easterly flow of $7 \mathrm{~m} \mathrm{~s}^{-1}$ is exiting the gorge. Companion SLP composites reveal a $\sim 6.5$ - $\mathrm{hPa}$ downgradient configuration from the interior to the coast. Nearly $70 \%$ of that gradient is confined to the adjacent sites flanking the gorge at DLS and TDE. Conditions are coolest and driest in the basin $\left(2^{\circ} \mathrm{C}, 3.8 \mathrm{~g} \mathrm{~kg}^{-1}\right)$ and warmest and most moist at the coast $\left(8^{\circ} \mathrm{C}, 5.2 \mathrm{~g} \mathrm{~kg}^{-1}\right)$. A well-defined trend in total precipitation accumulation spans the surface sites, from $\sim 85 \mathrm{~mm}$ in the dry continental interior to $\sim 1450 \mathrm{~mm}$ at the coast where landfalling storms have maximum impact. 

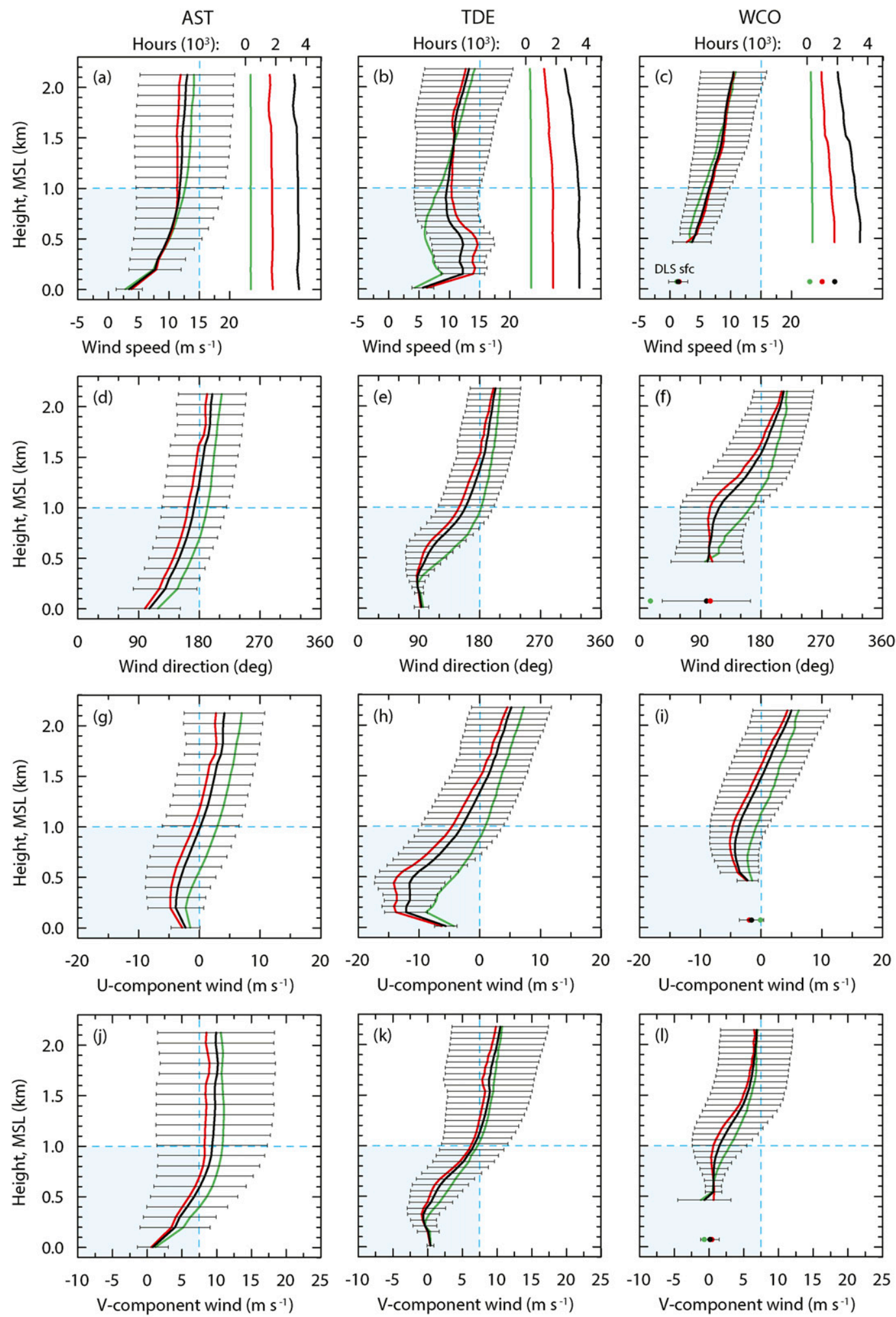

$$
\text { - all } 92 \text { events } \quad-23 \text { strongest } \quad-23 \text { weakest }
$$

FIG. 3. Composite mean wind profiles with horizontal standard deviation bars (black) at (left) AST, (center) TDE, and (right) WCO, based on the 92 gap-flow cases observed at TDE: (a)-(c) total wind speed 


\section{2) STRATIFIED WIND PROFILER COMPOSITES}

We stratified the 92 gap-flow cases at TDE into top and bottom quartiles based on the strength of the easterly component in the core of the gap jet and on the depth of the gap flow. Composite wind profiles and surface values were generated for the 23 strongest and weakest cases (19.7-13.7 and 10.2-5.2 $\mathrm{m} \mathrm{s}^{-1}$, respectively) and the 23 deepest and shallowest events (1087-667 and 445-335 m MSL, respectively). These stratification classes are composed of 1808 , 359,1365 , and $444 \mathrm{~h}$, respectively, and are shown with their composite mean counterparts in Figs. 3 and 4 (red and green profiles) and Figs. 5 and 6 (red and green bars). Table 3 contrasts the stratified statistical results of the mean gap-flow characteristics at TDE.

Stratification results based on gap-jet strength at TDE are presented in Figs. 3 and 5. The vertical structure of the strong composite profiles at TDE (Fig. 3, middle column) mirror those of the full 92-case composite. The magnitude of the total speed and $U$ in the strong composite is slightly larger than in the full composite below $1.5 \mathrm{~km}$, with the greatest difference of $\sim 3 \mathrm{~m} \mathrm{~s}^{-1}$ occurring in the gap-flow layer between 200 and $600 \mathrm{~m}$ MSL. In contrast, the weak composite profiles exhibit significant structural differences below $1 \mathrm{~km}$ MSL, most notably a shallow and weak gap jet. Above the weak composite gap jet, the flow is rotated $10^{\circ}-30^{\circ}$ clockwise relative to the two other composites. The stratified composite profiles at WCO and AST (Fig. 3, right and left columns, respectively) show comparable contrasts to those at TDE. Table 3 reveals that the strong-quartile events are, on average, much longer lived, deeper, and capped by stronger vertical shear than their weak counterparts. At the surface (Fig. 5), the most notable differences in the strong composites (middle column) relative to their weak counterparts (right column) are: 1) $\sim 4 \mathrm{~m} \mathrm{~s}^{-1}$ stronger surface flow at TDE, 2) $\sim 4 \mathrm{hPa}$ larger pressure difference from the interior to the coast, and 3) uniformly cooler and drier from the interior to the coast.
Composite gap-flow results stratified by depth are presented in Figs. 4 and 6. The vertical structure of the deep-quartile composite profiles at TDE is generally similar to those of the 92-case composites, although the easterly gap jet is $2 \mathrm{~m} \mathrm{~s}^{-1}$ stronger and the flow is rotated counterclockwise by $\sim 10^{\circ}-30^{\circ}$ above the jet, resulting in easterly component flow $400 \mathrm{~m}$ deeper (Fig. 4, middle column). In contrast, the shallow gap-flow composite profiles are markedly different than their deep counterparts. Most notably, the gap jet is weaker and closer to the ground and the easterly flow is considerably shallower. Comparable structural differences between the deep and shallow profiles are also observed at WCO and AST (Fig. 4, right and left columns, respectively). The deep events are, on average, longer lived, stronger, and with weaker capping vertical shear than their shallow counterparts (Table 3). At the surface (Fig. 6), the deep events are drier and have a modestly larger along-gorge SLP gradient than their shallower counterparts. Also, the deep events receive roughly half the precipitation as their shallower counterparts despite the fact that the deep events contain three times more hours. We will address this interesting result from a dynamical perspective in the follow-on subsection.

\section{3) STRATIFIED SYNOPTIC-SCALE COMPOSITES}

To explore the synoptic-scale control of gap-flow strength and depth at TDE, composite mean analyses are generated from the CFSv2 that correspond to the top and bottom quartiles of these gap-flow metrics (Figs. 7, 8). Those 6-h CFSv2 analyses that fall within the gap-flow date/time ranges shown in Table 2 are included in the gridded composite means. While the CFSv2 is subject to model and data-assimilation changes over time, owing to its operational implementation, these potential changes are not likely to significantly bias or influence the synoptic-scale interpretations of the composite means. A total of 308, 66, 232, and 81 CFSv2 analyses are included in the synoptic composites for the strongest,

\footnotetext{
$\longleftarrow$

$\left(\mathrm{m} \mathrm{s}^{-1}\right)$, (d)-(f) wind direction $\left(^{\circ}\right)$, (g)-(i) $U$-component (i.e., zonal) wind speed $\left(\mathrm{m} \mathrm{s}^{-1}\right)$, and (j)-(l) $V$-component (i.e., meridional) wind speed $\left(\mathrm{m} \mathrm{s}^{-1}\right)$. The wind speeds and directions are scalar averages, whereas the $U$ and $V$ components are vector averages. Also shown in each panel are the mean wind profiles at AST, TDE, and WCO that are stratified by the 23 strongest and weakest gap-flow events observed at TDE (red and green, respectively). The top row also shows profiles of the number of hourly points per range gate for the 92 -case mean profiles and the stratified profiles. Composite surface data from DLS accompany the profiles at WCO. The dashed blue lines and shading are shown to help facilitate comparison between panels.
} 

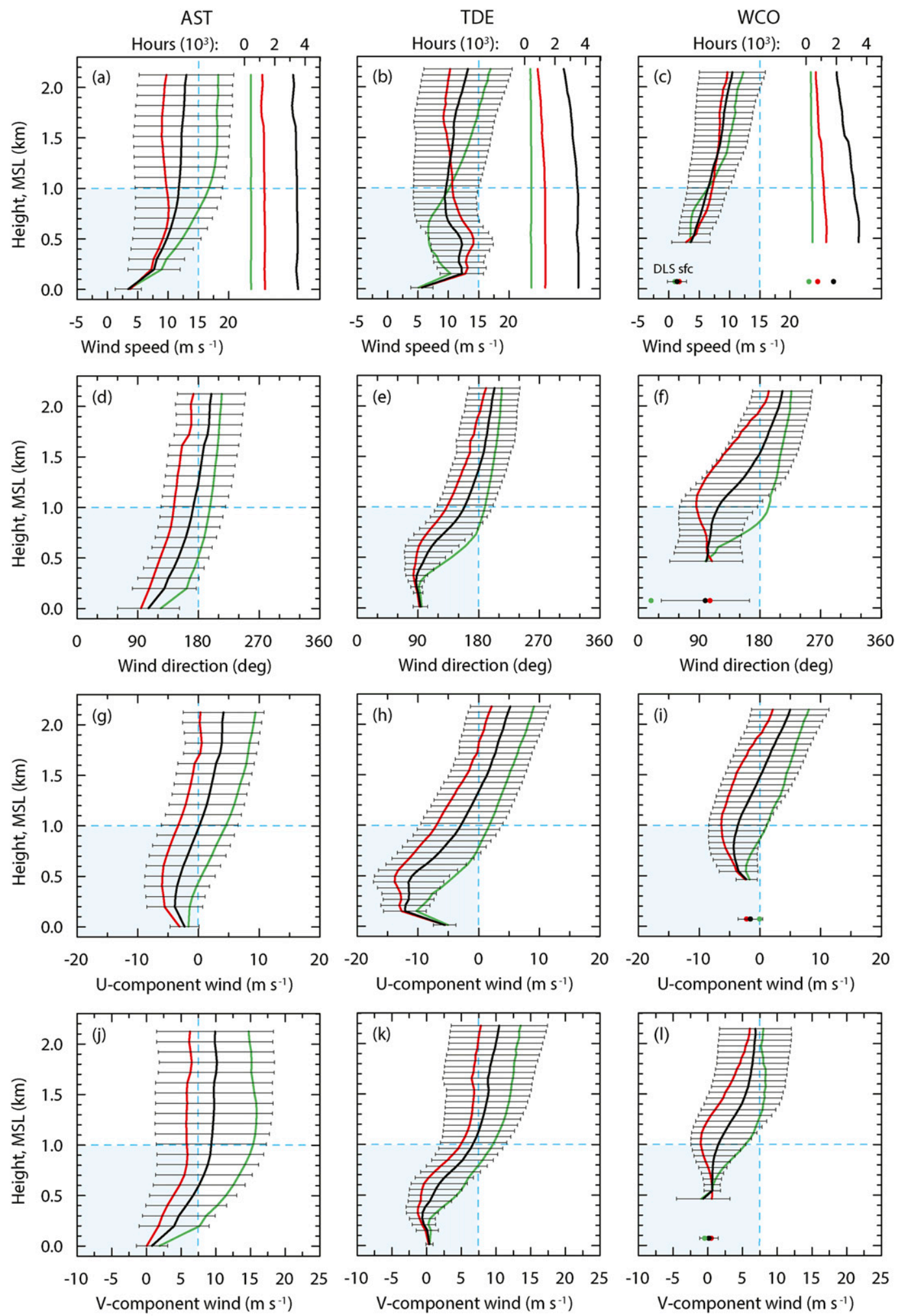

$$
\text { - all } 92 \text { events - } 23 \text { deepest } \quad-23 \text { shallowest }
$$

FIG. 4. As in Fig. 3, but for mean wind profiles stratified by the 23 deepest and shallowest gap-flow events at TDE (red and green, respectively). 

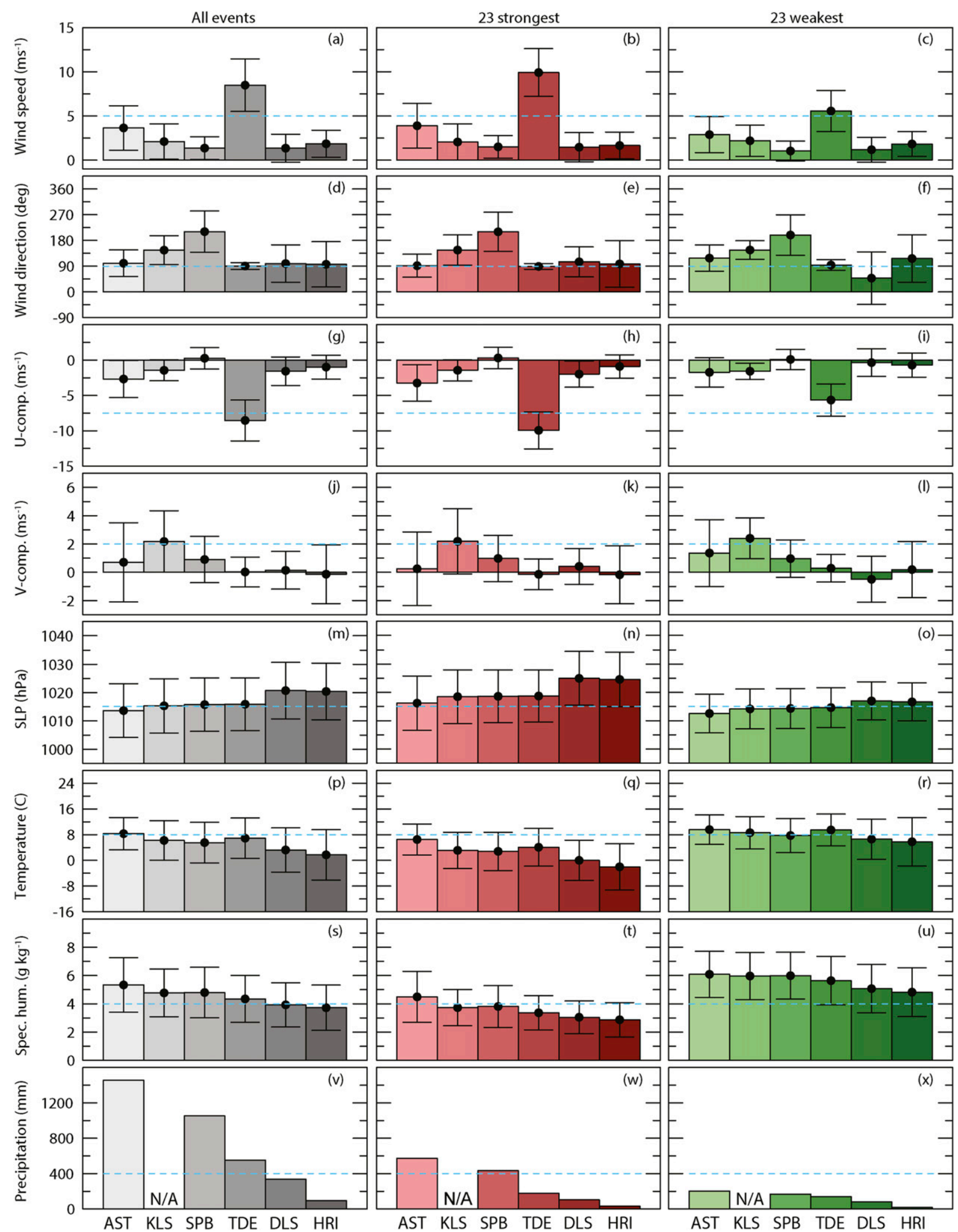

FIG. 5. Composite mean surface data (six sites labeled at the bottom) with vertical standard deviation bars, based on the gap-flow events observed at TDE: (left) all 92 gap-flow events, (center) the 23 strongest gap-flow events, and (right) the 23 weakest gap-flow events. Surface variables include (a)-(c) wind speed $\left(\mathrm{m} \mathrm{s}^{-1}\right)$, (d)-(f) wind direction $\left({ }^{\circ}\right)$, (g)-(i) $U$-component (i.e., zonal) wind speed ( $\left.\mathrm{m} \mathrm{s}^{-1}\right)$, (j)-(l) $V$-component (i.e., meridional) wind speed $\left(\mathrm{m} \mathrm{s}^{-1}\right),(\mathrm{m})-(\mathrm{o})$ sea level pressure $(\mathrm{hPa}),(\mathrm{p})-(\mathrm{r})$ temperature $\left({ }^{\circ} \mathrm{C}\right),(\mathrm{s})-(\mathrm{u})$ specific humidity $\left(\mathrm{g} \mathrm{kg}^{-1}\right)$, and $(\mathrm{v})-(\mathrm{x})$ total precipitation accumulation $(\mathrm{mm})$. Reliable precipitation measurements were unavailable at KLS. The wind speeds and directions are scalar averages, whereas the $U$ and $V$ components are vector averages. The dashed blue lines are shown to help facilitate comparison between panels. 

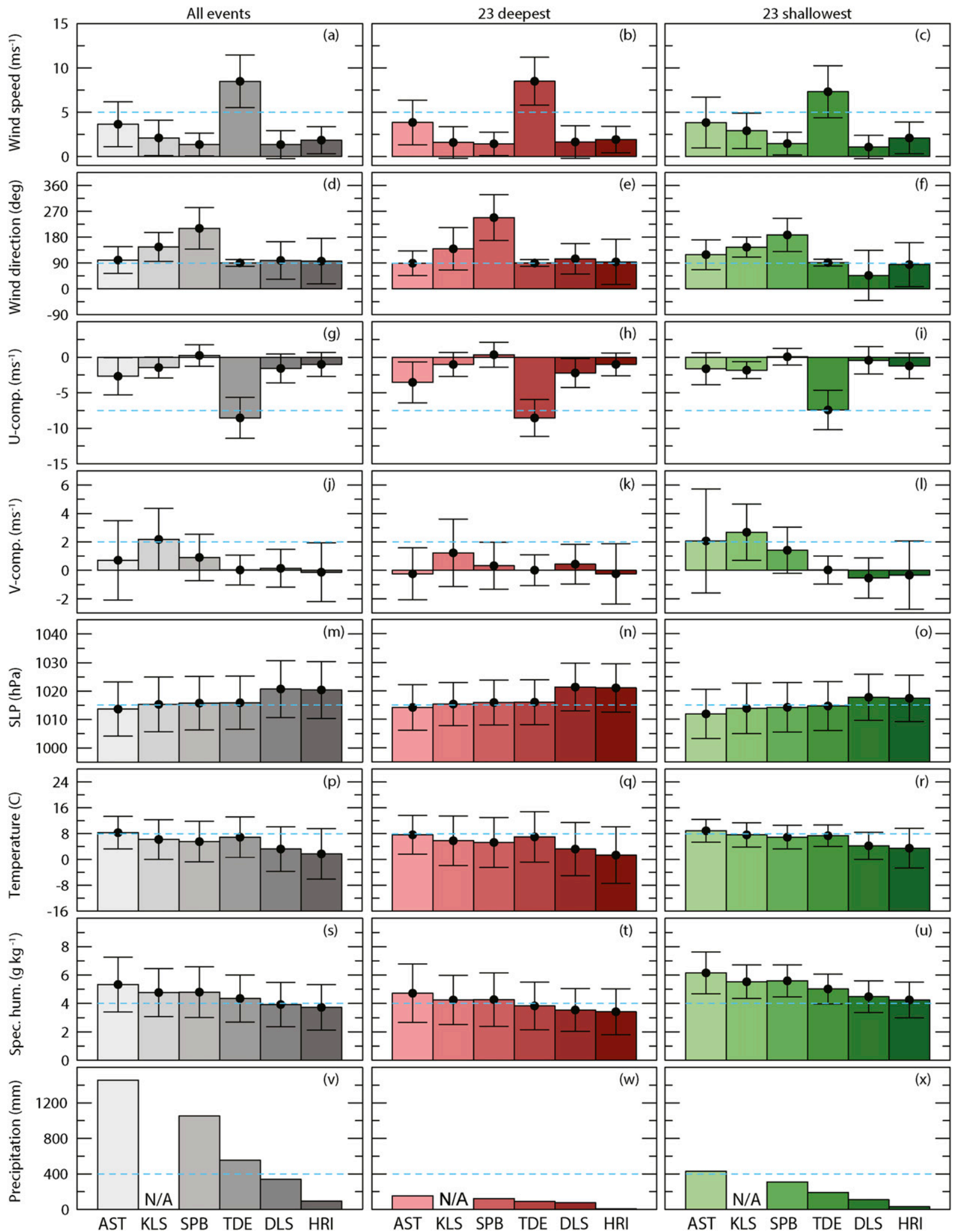

FIG. 6. As in Fig. 5, but for mean surface data stratified by the (center) 23 deepest and (right) 23 shallowest gap-flow events at TDE. 
TABLE 3. Composite summary statistics of gap-flow cases from the Troutdale wind profiler for the two cool seasons. In addition to showing the (top row) full 92-case mean values, the results are also stratified by the following characteristics into (middle three rows) upper and lower quartiles of 23 cases each for gap-flow jet strength and (bottom three rows) depth. The wind direction of the gap-flow jet is excluded from this table because there is very little variability about the $\sim 90^{\circ}$ mean.

\begin{tabular}{|c|c|c|c|c|c|}
\hline Metric & $\begin{array}{l}\text { Gap-flow event } \\
\text { (No. of hours) }\end{array}$ & $\begin{array}{l}\text { Gap flow jet: } \\
\text { Altitude } \\
\text { of max easterly } \\
\text { flow (m, MSL) }\end{array}$ & $\begin{array}{l}\text { Gap flow jet: } \\
\text { Magnitude } \\
\text { of max easterly } \\
\text { flow }\left(\mathrm{m} \mathrm{s}^{-1}\right)\end{array}$ & $\begin{array}{c}\text { Gap flow } \\
\text { depth (m, MSL) }\end{array}$ & $\begin{array}{l}\text { Zonal vertical } \\
\text { wind shear atop } \\
\text { the gap flow } \\
\left(\mathrm{m} \mathrm{s}^{-1} \mathrm{~km}^{-1}\right)\end{array}$ \\
\hline 92-case mean & 38.5 & 363.3 & 12.0 & 570.4 & 25.9 \\
\hline Strongest 23 , mean & 78.6 & 475.0 & 15.7 & 693.4 & 31.9 \\
\hline Weakest 23 , mean & 15.6 & 261.1 & 8.7 & 457.9 & 22.6 \\
\hline 2 -sided $t$-test significance, strength & $100 \%$ & $100 \%$ & $100 \%$ & $100 \%$ & $99.9 \%$ \\
\hline Deepest 23 , mean & 59.3 & 566.2 & 14.1 & 779.0 & 20.9 \\
\hline Shallowest 23 , mean & 19.3 & 199.8 & 10.0 & 403.0 & 25.8 \\
\hline 2-sided $t$-test significance, depth & $99.9 \%$ & $100 \%$ & $100 \%$ & $100 \%$ & $92.0 \%$ \\
\hline
\end{tabular}

weakest, deepest, and shallowest stratifications, respectively. ${ }^{1}$ Composite means are accompanied by their anomaly counterparts, which are calculated by subtracting the long-term (1981-2010) CFSR averages composed of the specified 6-h days/times from the CFSv2 composite mean fields based on those same days/times. These temporally nonoverlapping gridded datasets are both employed because the CFSR (CFSv2) does not extend sufficiently forward (backward) in time.

All four sets of synoptic composites (Figs. 7, 8) display common attributes, including a progressive $1000-500 \mathrm{hPa}$ trough offshore of the CRG, a ridge axis east of the gorge, an axis of warm maritime air at $1000 \mathrm{hPa}$ just offshore of the coast, polar cold-frontal baroclinicity farther offshore, and cold continental air east of the gorge in the Columbia basin. The westward increase in $1000-\mathrm{hPa}$ temperature along the gorge and the associated westward decrease in $1000-\mathrm{hPa}$ geopotential height favor westward-directed gap flows down the pressure gradient in the gorge.

Despite commonalities, these synoptic composites also possess unique attributes, which, ultimately, help explain differences in the wind profiler and surface composite structures described earlier. Focusing first on gap-flow strength, the strong composite at $500 \mathrm{hPa}$ exhibits weaker onshore geostrophic flow than its weak counterpart (Figs. 7a,b), consistent with the upper portion of the wind profile composites at TDE and AST showing stronger flow aloft with weak gap-flow events (Figs. 3a,b). The height anomalies at $500 \mathrm{hPa}$ for the strong gap-flow composite show a weaker offshore minimum and a stronger interior maximum than the

\footnotetext{
${ }^{1}$ Randomized composite experiments were conducted to explore possible biases resulting from differing sample sizes. No significant differences were found.
}

weak gap-flow composite. This anomaly dipole is oriented southwest-northeast for the strong composite and northwest-southeast for the weak composite. Similar anomaly characteristics are found in the 1000-hPa height composites (Figs. 7c,d), resulting in a stronger westward decrease in geopotential height along the gorge for the strong gap-flow events. The companion temperature composite at $1000 \mathrm{hPa}$ for strong cases reveals (Fig. 7e) widespread cold air over the northern Rockies and Columbia basin. The prevalence of ridging aloft in the northern interior favors the development of cold arctic anticyclogenesis in the lower troposphere in combination with boundary layer radiative cooling. In contrast, much weaker ridging aloft in the northern interior for the weak gap-flow cases is unfavorable for arctic anticyclogenesis or boundary layer cooling, hence cold air is absent in the interior at $1000 \mathrm{hPa}$ (Fig. 7f). Correspondingly, the weak gap-flow composite at the WCO wind profiler (Fig. 3f) reveals shallow easterly flow, most likely due to the lack of a significant cold pool. In summary, the strong gap-flow events are governed by a cold interior anticyclone whereas the weak events are dominated by an offshore cyclone.

The synoptic composites for deep-versus-shallow gapflow events (Fig. 8) resemble those of the strong-versusweak events (Fig. 7), consistent with the fact that strong (weak) events are typically deep (shallow) (Table 3). Nevertheless, there are substantial differences in the details. The deep gap-flow composites (Figs. 8a,c) show negative height anomalies offshore that are larger and displaced southeast of the corresponding strong gapflow anomalies (Figs. 7a,c). Simultaneously, the interior positive height anomalies in the deep composites are northwest of and larger than the strong composites. These changes yield low-level geostrophic flow with a more pronounced westward component near and offshore of the coast for the deep gap-flow events (Fig. 8c), 

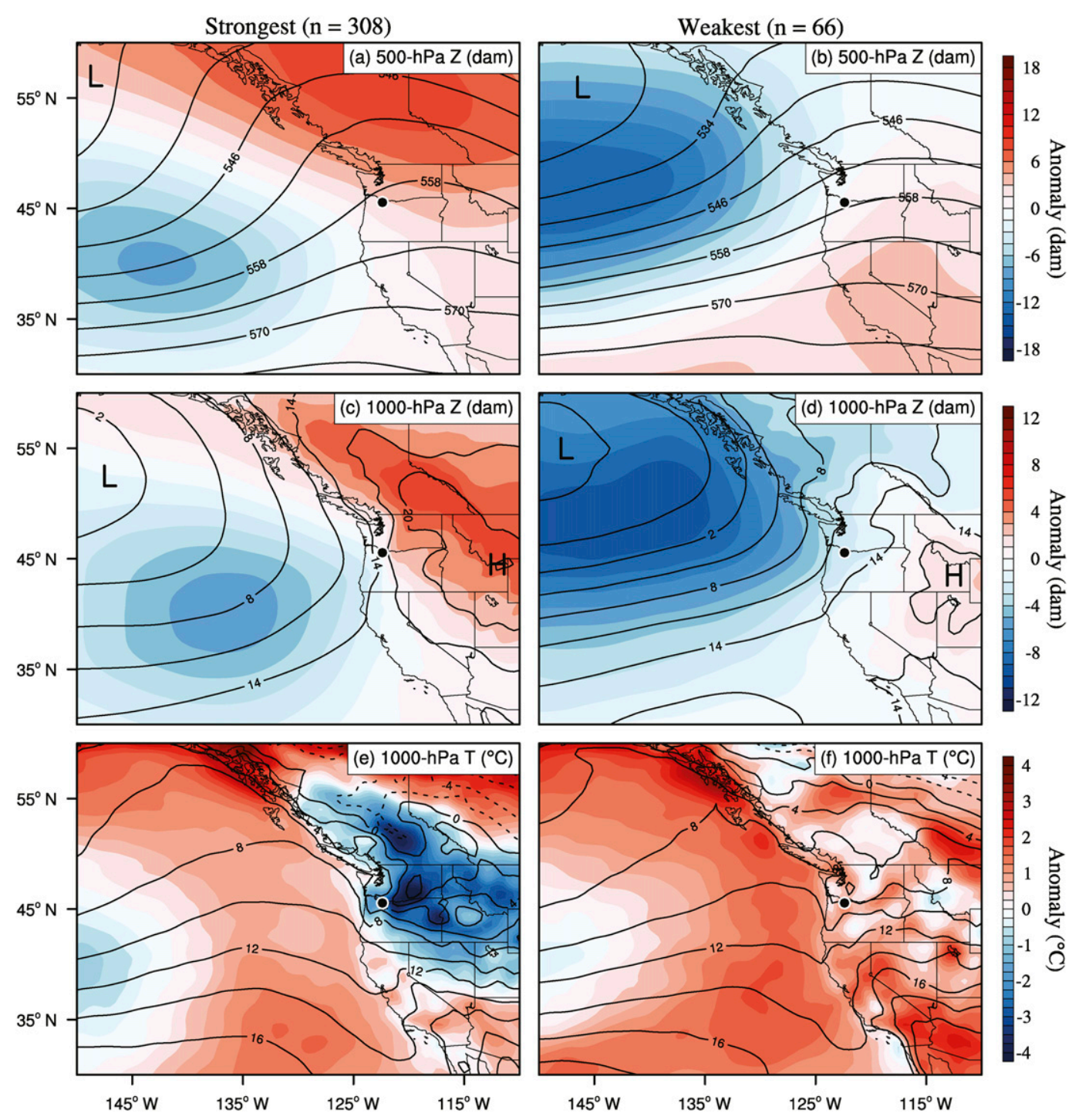

FIG. 7. Composite mean and anomaly analyses (solid and color-filled contours, respectively) derived from NOAA's Climate Forecast System gridded datasets, stratified by the (left) 23 strongest and (right) 23 weakest gap-flow events observed at TDE (location shown by black dot): (a),(b) 500-hPa geopotential height (dam); (c),(d) 1000-hPa geopotential height (dam); and (e),(f) 1000-hPa temperature $\left({ }^{\circ} \mathrm{C}\right)$. The anomaly reference period is 1981-2010. The variable $n$ at the top of each column shows the number of 6 -h analyses used in the strong and weak composites.

which suggest that such events represent a combination of channeled and synoptically forced flow. Correspondingly, the deep gap-flow composite wind profiles (Figs. 4d-f) show wind direction profiles through their 2.3-km depth that are rotated counterclockwise relative to the 92-case and shallow composites. Finally, the deep cases have warmer interior temperatures and colder offshore temperatures than the strong ones (Figs. 8e, $7 \mathrm{e}$ ), which further suggests that these deeper cases are not driven solely by the magnitude of the interior cold pool or low-level temperature (and, by extension, SLP) gradient along the gorge but also require phasing with synoptic-scale forcings.

\section{b. Temporal evolution}

We now explore the composite temporal evolution of the 92 gap-flow events observed at TDE. Hourly data from these events have been placed into 20 equally distributed temporal bins and then averaged, where time is expressed as a normalized fraction of the total gapflow duration (Figs. 9, 10). Composite temporal characteristics of gap-jet strength and gap-flow depth are 

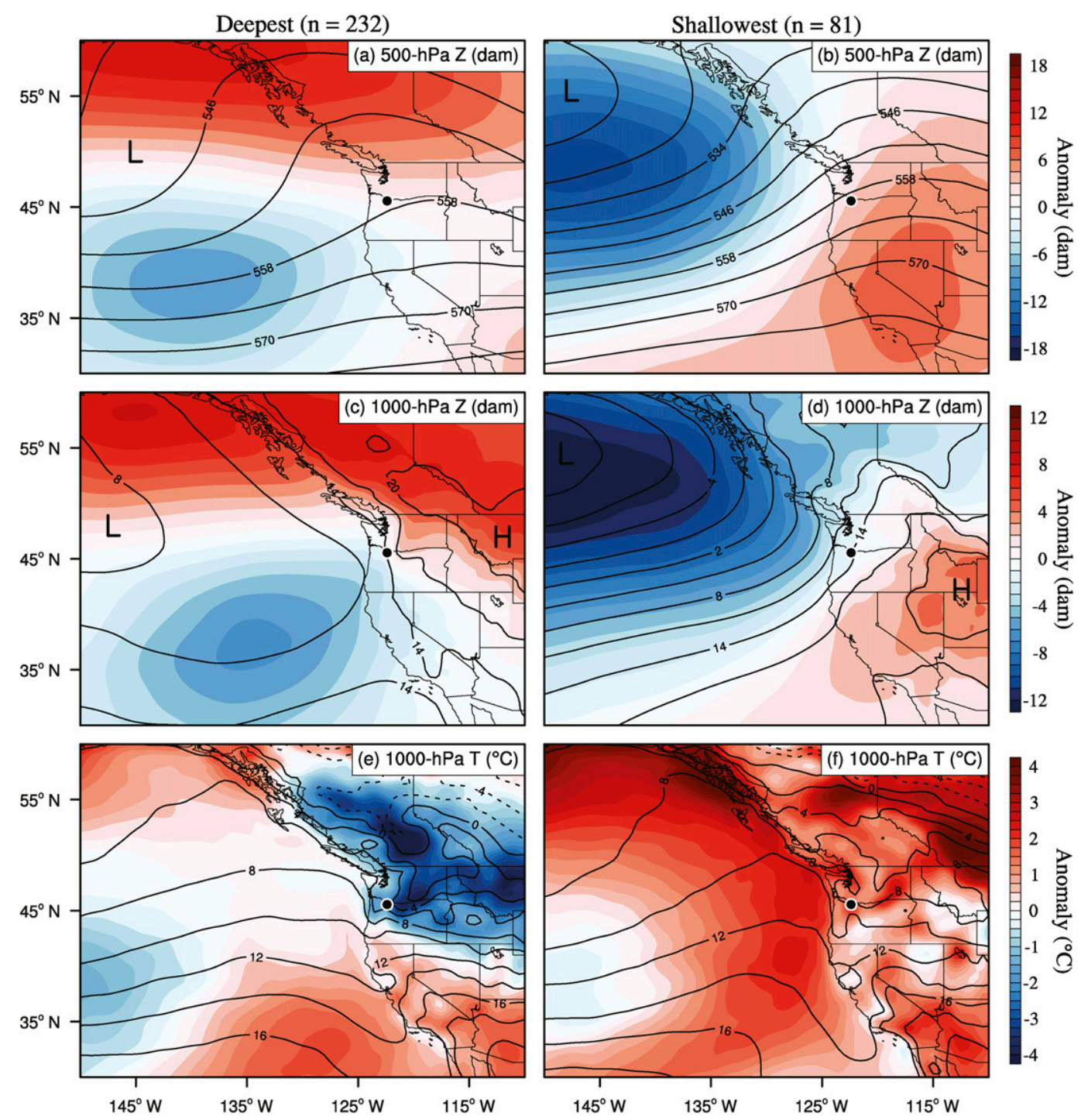

FIG. 8. As in Fig. 7, but stratified by the (left) 23 deepest and (right) 23 shallowest gap-flow events observed at TDE.

presented in Figs. 9a and 9b, respectively, where these metrics are determined on an hourly basis using the gapflow auto-detection algorithm in Neiman et al. (2018). The average magnitude of the gap jet commences weak, strengthens to $>\sim 15 \mathrm{~m} \mathrm{~s}^{-1}$ during the middle of the composite event, and subsequently weakens. The greatest number of hourly gap-jet speeds in the bottom quartile $\left(\leq 10.8 \mathrm{~m} \mathrm{~s}^{-1}\right)$ populate the wings of the event, while those hourly speeds in the top quartile $\left(\geq 16.8 \mathrm{~m} \mathrm{~s}^{-1}\right)$ concentrate in the middle of the event. Above the gap flow at $1.5 \mathrm{~km} \mathrm{MSL}$, weak southeasterly flow of $\sim 5 \mathrm{~m} \mathrm{~s}^{-1}$ strengthens to $7.5 \mathrm{~m} \mathrm{~s}^{-1}$ southerlies during peak gap-jet strength, and the flow continues to strengthen and veer to $\sim 12.5 \mathrm{~m} \mathrm{~s}^{-1}$ southwesterlies with the approach of an offshore trough and associated polar cold front. The mean depth of the composite gap-flow event commences at $600 \mathrm{~m}$ MSL, increases to $700 \mathrm{~m}$ MSL $17.5 \%$ into the event, and then decreases thereafter (slowly at first, then more quickly). The greatest number of top-quartile hourly depths ( $\geq 770 \mathrm{~m}$ MSL) occur during the middle of the event, while the bottom-quartile depths $(\leq 470 \mathrm{~m}$ MSL) are skewed to the final $20 \%$ of the event. The simultaneous decrease in gap-flow depth with the increase in maritime southwesterlies aloft suggest that the gap flow is eroding via vertical turbulent mixing.

The composite temporal evolution of hourly SLP tendency at TDE and DLS at opposite ends of the gorge and of the along-gorge pressure gradient between DLS and TDE are shown in Fig. 9c. The tendency at TDE ranges between -0.15 and $-0.4 \mathrm{hPa} \mathrm{h}^{-1}$ for most of the composite due to an approaching landfalling cyclone, whereas the final temporal bin changes sign with 

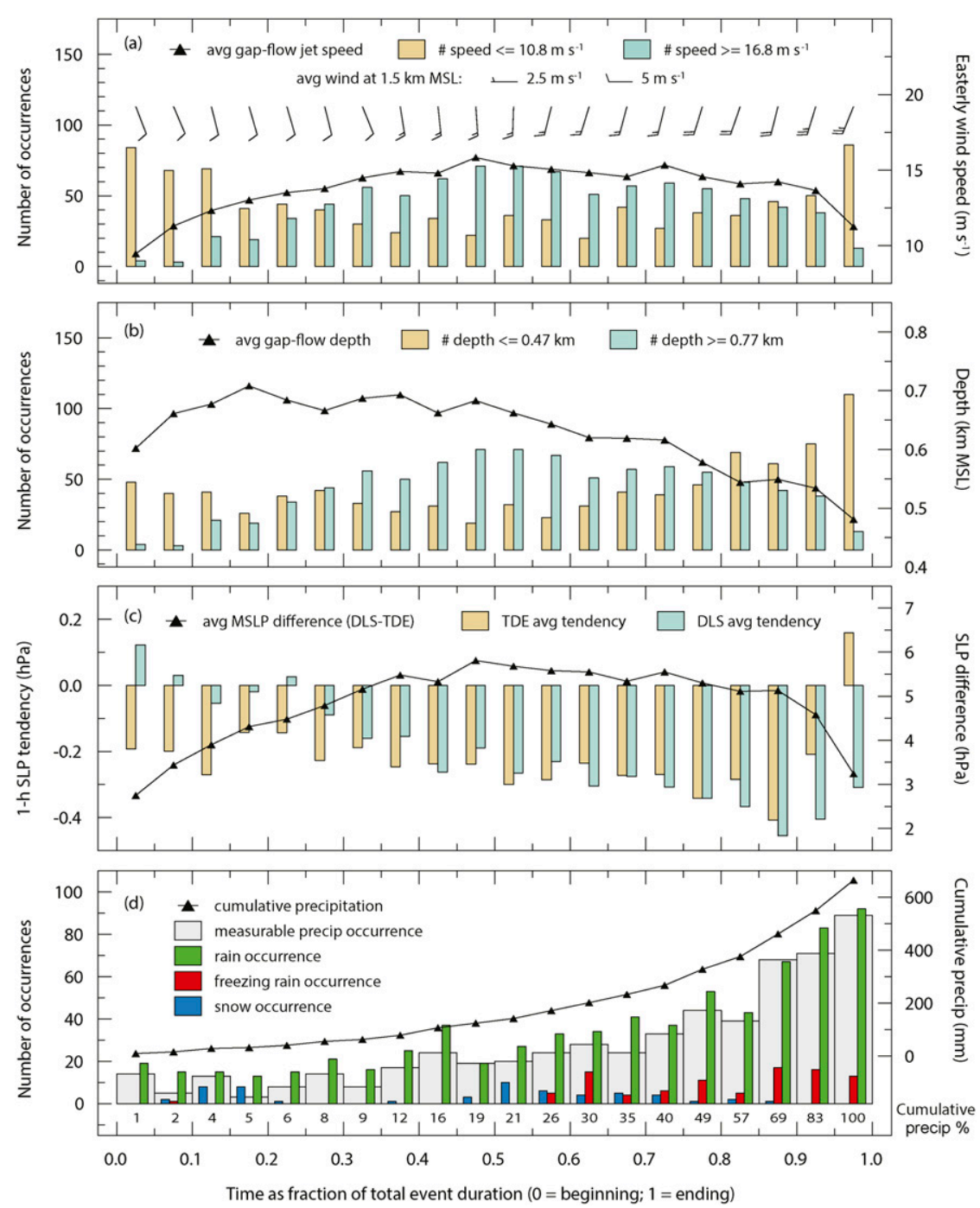

FIG. 9. Composite normalized temporal distribution of key observations during the 92 gapflow events observed at TDE, where time is expressed as the fraction of the total event duration (beginning $=0$, end $=1$, interval $=0.05)$. (a) - (c) All 35461 -h periods during the gap-flow events, and (d) the 5651 -h periods with measureable precipitation during those events. (a) Wind velocity at TDE. Histogram bars (see key): number of 1-h occurrences in the bottom and top quartiles of easterly wind speed ( $\leq 10.8$ and $\geq 16.8 \mathrm{~m} \mathrm{~s}^{-1}$, respectively) in the core of the gap jet. Black curve: average easterly wind speed $\left(\mathrm{m} \mathrm{s}^{-1}\right)$ of the gap jet. Wind barbs (barbs: $5 \mathrm{~m} \mathrm{~s}^{-1}$; half-barbs: $2.5 \mathrm{~m} \mathrm{~s}^{-1}$ ): average wind velocity at $1.5 \mathrm{~km}$ MSL. (b) Gap-flow depth at TDE. Histogram bars (see key): number of 1-h occurrences in the bottom and top quartiles of gap-flow depth ( $\leq 0.47$ and $\geq 0.77 \mathrm{~km} \mathrm{MSL}$, respectively). Black curve: average depth of the gap flow (km MSL). (c) SLP characteristics at TDE and DLS. Histogram bars (see key): Average 1-h SLP tendency (hPa) at TDE and DLS. Black curve: SLP difference (hPa) between DLS and TDE. (d) Precipitation characteristics at TDE. Histogram bars (see key): number of 1-h occurrences with measureable precipitation, rain, freezing rain, and snow. Black curve: cumulative precipitation starting at time $=0$. The cumulative precipitation percentage (rounded to the nearest whole number) is shown below each histogram-bar grouping.

the initial passage of a polar cold front. The tendency at DLS is initially $>0$, quite likely in response to building high pressure in the continental cold pool in the Columbia basin. After one-quarter of the composite event transpires, the tendency becomes consistently negative with the approach of the Pacific cyclone. During the final $30 \%$ of the composite, the negative SLP tendency is larger at DLS than at TDE, quite likely 


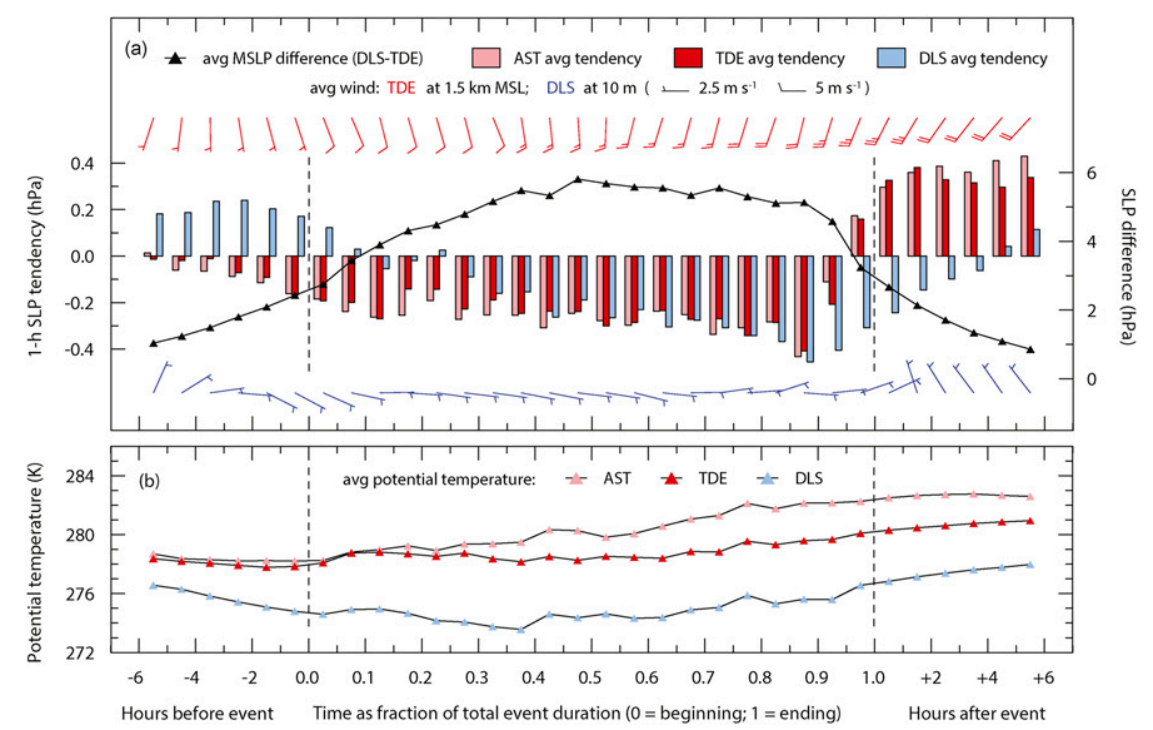

FIG. 10. (a) As in Fig. 9c, but that the time axis extends $\pm 6 \mathrm{~h}$ beyond the outer bounds of the composite gap-flow event (vertical dashed lines), the color key is different, the SLP characteristics at AST are included, and the average 1-h near-surface wind barbs at DLS and $1.5 \mathrm{~km}$ MSL barbs at TDE are also included. (b) Corresponding time series of composite potential temperature (K) at AST, TDE, and DLS (see key).

because the depth of the interior cold pool is decreasing with vertical turbulent mixing from strengthening southwesterlies aloft. The SLP gradient between DLS and TDE increases from $2.75 \mathrm{hPa}$ at the start of the composite to nearly $6 \mathrm{hPa}$ at the half-way mark and then decreases to $5.13 \mathrm{hPa}$ at $90 \%$ through the event. In the last $10 \%$, the SLP gradient decreases markedly with the initial polar cold-frontal passage at TDE. Comparing the composite time series of SLP gradient with gap-jet speed reveals a high correlation of 0.98 , consistent with Sharp and Mass (2004) who show $r^{2}=0.80$ for hourly surface easterly wind speed at TDE versus hourly SLP gradient between DLS and TDE during a 2-yr period. Similarly, the wind profiler study of Neiman et al. (2006) highlights a 5.75-day gap-flow case through California's Petaluma Gap, where $r^{2}=0.86$ for the hourly relationship between easterly component flow in the $250-550 \mathrm{~m}$ MSL layer versus the along-gap SLP gradient. A physical link is absent between the DLS-TDE SLP gradient and gap-flow depth at TDE, where $r^{2}=0.05$.

To gain additional meteorological insights on gapflow evolution, a temporally expanded version of Fig. 9c is shown in Fig. 10, which also includes the following new hourly averaged data: SLP tendency at the coast at AST, surface wind at DLS, and 2-m potential temperature $(\theta)$ from all three sites. SLP tendencies west of the gorge at TDE and AST track in unison throughout the composite time series, including during the SLP rises following gapflow conditions with the composite polar cold-frontal passage (Fig. 10a). The $\theta$ at TDE and AST also track in unison, but only prior to, and at the onset of, gap-flow conditions (Fig. 10b). Thereafter, steady warming ensues at AST in the precold-frontal maritime air mass, whereas warming doesn't commence at TDE until $\sim 60 \%$ through the composite gap-flow event. The wind shift with the cold-frontal passage at $1.5 \mathrm{~km}$ MSL is captured late in the time series, where strong precoldfrontal southwesterlies veer and weaken in conjunction with the SLP rises at TDE and AST (Fig. 10a). During this period, $\theta$ along the coast at AST starts to decrease slightly in postcold-frontal conditions, while it continues to increase at TDE as the gap flow erodes at the mouth of the gorge (Fig. 10b). The SLP tendency at DLS exhibits markedly different characteristics than at its western counterparts. Namely, rises are observed during the lead-in to gap-flow conditions as the Columbia basin shallow cold pool intensifies (note the companion decrease in $\theta$ ), while, during the cessation of gap-flow conditions, falls transition to weak rises as the influence of the interior cold pool wanes and postfrontal ridging increases. During this latter period, the surface flow at DLS transitions from easterly to northwesterly and the surface $\theta$ attains its warmest values, likely in response to increasing postcold-frontal downslope westerly component flow aloft east of the Cascades eroding the cold pool from above (e.g., Whiteman et al. 2001).

Figure 9d highlights temporal characteristics of hourly precipitation at TDE during the composite gap-flow 
event when $664 \mathrm{~mm}$ accumulates. It starts relatively dry, where $19 \%$ of the accumulation occurs during the first half of the composite, and ends wet, where nearly onethird accumulates in the last $10 \%$. Measureable precipitation and rain occurrences are skewed to the latter part of the event. The increasing wetness with time coincides with the landward approach of extratropical cyclone conditions and polar cold fronts. The temporal distribution of snow and freezing rain differ from each other and from rain. Namely, snowfall is favored during the early stage of gap-flow events when cold gap flow is deepest and during the middle of the events when the gap jet is strongest. In contrast, freezing rain occurs during the latter half of gap-flow events when the depth of the cold gap flow is decreasing significantly with the advection of warm and moist southwesterly precoldfrontal flow ahead of a progressive trough aloft.

Another aspect of temporal evolution to consider is whether there are any diurnal or interseasonal impacts on gap flows. Figure 11 presents diurnal histograms of event begin times and end times and monthly (cool-season) histograms of hourly gap-flow occurrence for the full 92-case inventory. The event begin times (Fig. 11a) are grouped mainly in the evening local time (LT). For example, 54 (i.e., $59 \%$ ) of event begin times are between 0100 and 0900 UTC (i.e., 1700-0100 LT), with a maximum number (14) occurring at 0500-0600 UTC (2100-2200 LT). This makes sense because cold pooling contributes to gap flow development, and cold pooling is maintained by radiational cooling during the night. In contrast, the end times occur more often during the morning hours LT (Fig. 11b). Consequently, 45 (i.e., $49 \%$ ) of the event end times are between 1200 and 2000 UTC (0400-1200 LT), with a maximum number (10) occurring at 1900-2000 UTC (1100-1200 LT) and a majority (26) within this period occurring between 1700 and 2000 UTC (0900-1200 LT). This makes sense because turbulent mixing associated with daytime heating can erode the interior cold pool (Zhong et al. 2001) and cause gap flows to diminish. The distributions of gap-flow depth and jet speed did not exhibit any notable diurnal behavior (not shown).

During the cool-season, $1026 \mathrm{~h}$ of gap flow (29\% of the total observed hours) occurred in January (Fig. 11c), which was nearly twice the number of occurrences in the second and third highest ranked months of December and February (533 and 576h, respectively). This midwinter signal coincided with longer-duration events (red text in Fig. 11c), where 811 (79\%) of the January gap-flow hours occurred during the longest-quartile events (Table 2) and were associated with an anomalously amplified synoptic-scale trough (ridge) of low (high) pressure over the eastern Pacific Ocean (Pacific
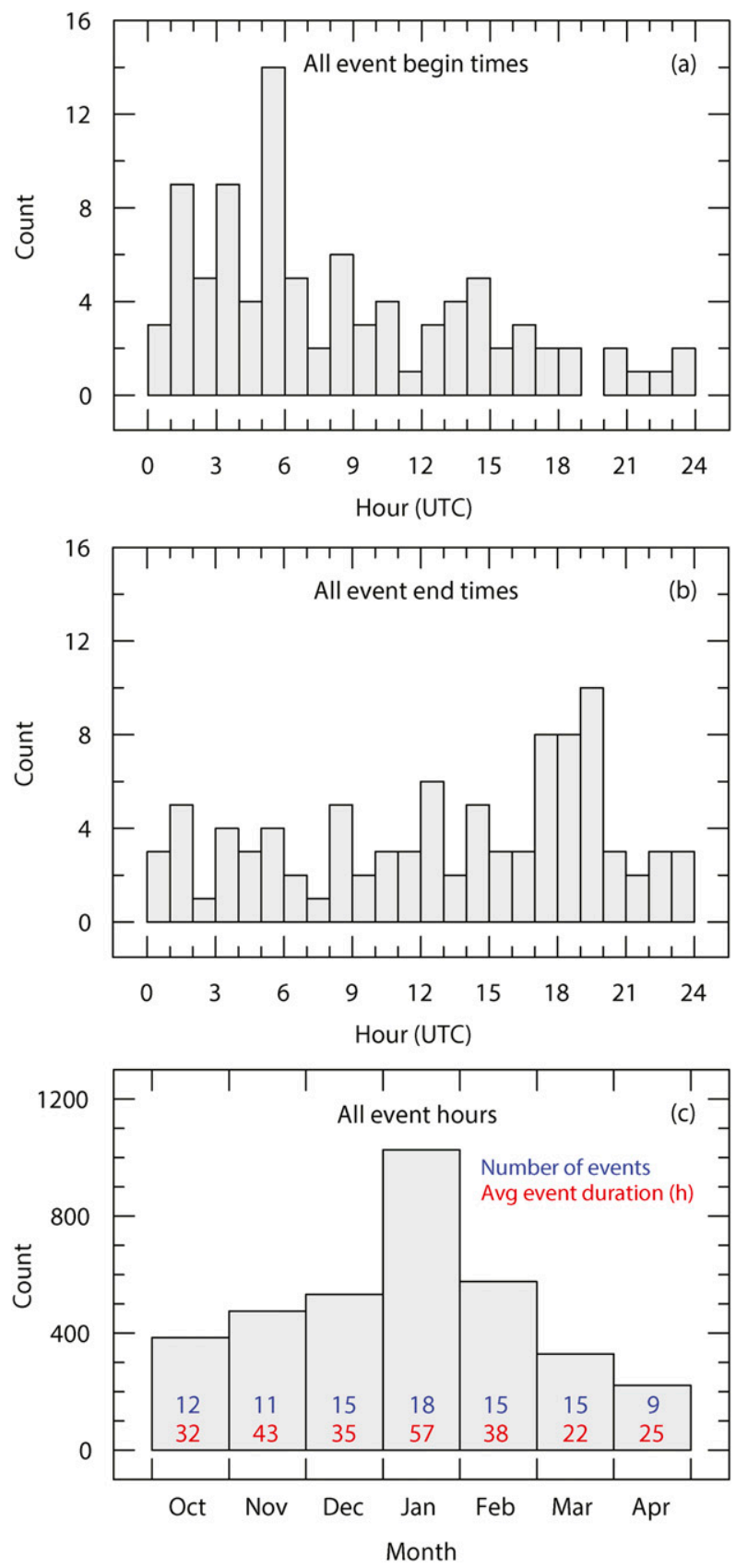

FIG. 11. Hourly distribution of (a) begin time and (b) end time, and (c) monthly distributions of hourly gap flow, for all 92 observed gap-flow events at TDE. The number of events (blue text) and average event duration (h; red text) for each month are shown at the bottom of the histogram bars in (c). Events that spanned month boundaries (November-December 2015; December-January 2015/16; January-February 2017) were split into six events.

Northwest and western British Columbia), which maintained strong radiational cooling and arctic outbreaks east of the CRG and warm advection off the Pacific Northwest coast (not shown). 


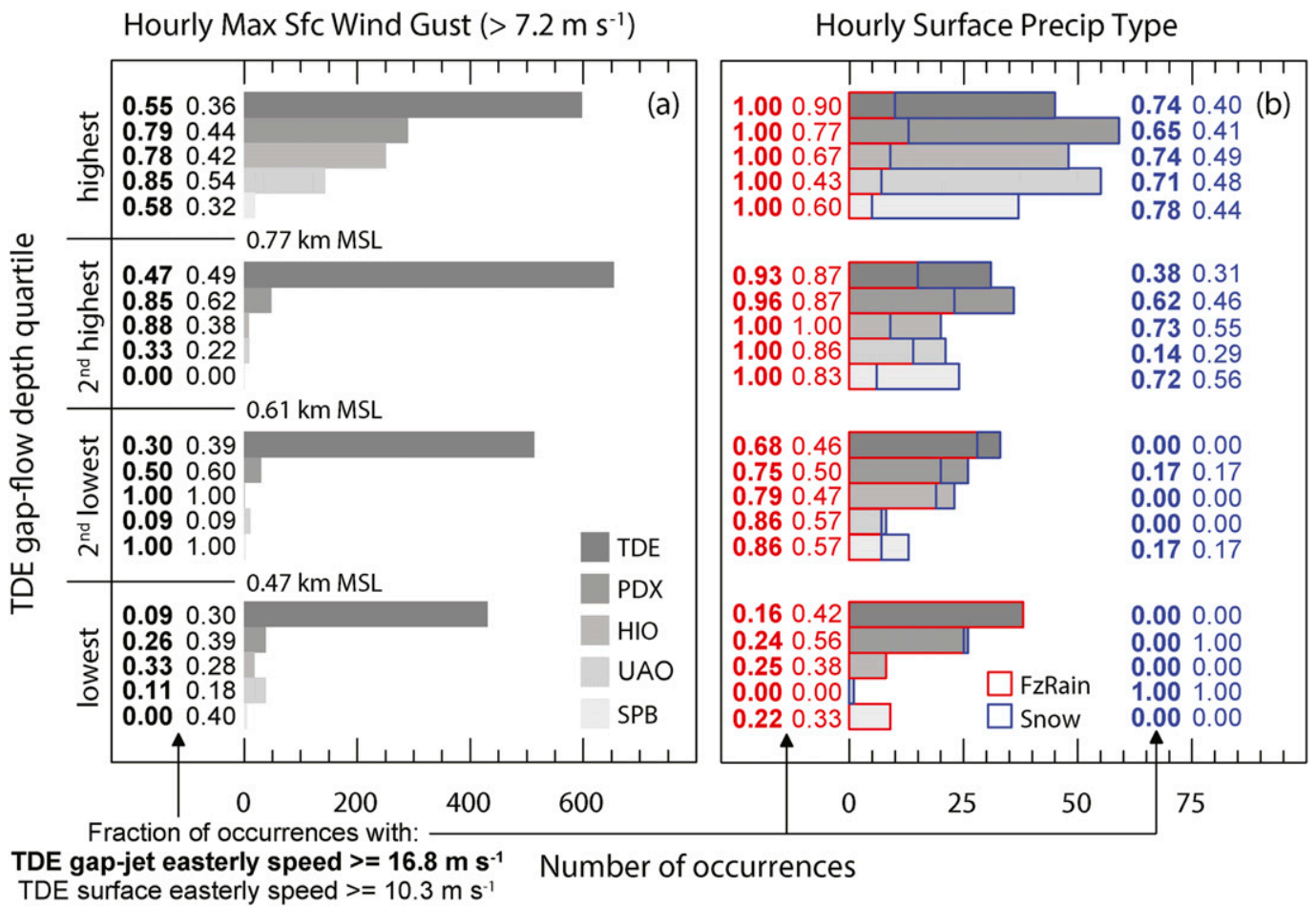

FIG. 12. Composite analysis of regional gap-flow impacts based on the 92-case gap-flow inventory observed at TDE: the number of occurrences of reported hourly (a) maximum surface wind gusts (i.e., $\geq 7.2 \mathrm{~m} \mathrm{~s}^{-1}$ ); and (b) winter precipitation type ( $\mathrm{red}=$ freezing rain, blue $=$ snow), observed at five surface sites in the Portland area (see gray-shaded key in (a) as a function of gap-flow depth (divided into four quartiles: $>0.77 \mathrm{~km}$ MSL, 0.61$0.77 \mathrm{~km}$ MSL, $0.47-0.61 \mathrm{~km}$ MSL, and $<0.47 \mathrm{~km}$ MSL). The fraction of occurrences with gap-jet easterly speeds exceeding $16.8 \mathrm{~m} \mathrm{~s}^{-1}$ at TDE (i.e., the top quartile of gap-jet values) are expressed numerically for the hourly occurrence of maximum surface wind gusts [left side of (a), bold black font], freezing rain [left side of (b), bold red font], and snow [right side of (b), bold blue font] at each of the five surface sites. The fraction of occurrences with surface easterly speeds exceeding $10.3 \mathrm{~m} \mathrm{~s}^{-1}$ at TDE (i.e., the top quartile of surface values) are also expressed numerically for the hourly occurrence of maximum surface wind gusts [left side of (a), regular black font], freezing rain [left side of (b), regular red font], and snow [right side of (b), regular blue font] at each of the five surface sites.

\section{Gap-flow impacts in the Portland metropolitan area}

Gap-flow events can result in strong winds and wintertype precipitation, both of which generate adverse societal impacts in the CRG and westward across the Portland metropolitan area. In this section, we first present a composite analysis (Fig. 12) showing linkages between gap-flow depth and strength observed by the TDE wind profiler during the 92 gap-flow cases and the resulting surface wind and precipitation impacts there and at four other sites around Portland (i.e., at PDX, HIO, UAO, $\mathrm{SPB})$. We then showcase three gap-flow events contained in the inventory to highlight further gap-flow characteristics that generate those impacts (Fig. 13). The gap-flow depth and gap-jet easterly speed are determined hourly using the auto-detection algorithm in Neiman et al. (2018).

The histograms in Fig. 12a depict the number of occurrences of hourly maximum wind gusts exceeding the minimum reported $7.2 \mathrm{~m} \mathrm{~s}^{-1}$ at the five surface sites as a function of gap-flow depth (divided into four quartiles). By far, the greatest number of surface gusts occur at the mouth of the CRG at TDE, totaling in the hundreds regardless of gap-flow depth. In contrast, farther west across the Portland metropolitan area at PDX, HIO, and UAO, gusty surface winds are associated primarily with the deepest quartile of gap flows. At the fardownriver site at SPB, gusty surface conditions are rare, regardless of gap-flow depth. The companion histograms in Fig. 12b show the number of occurrences of hourly winter-type precipitation at the five surface sites as a function of gap-flow depth. At TDE and PDX, the number of freezing rain hours mostly increase with decreasing gap-flow depth, consistent with snow melting to rain in the warm air aloft and refreezing on contact with the surface in shallow, cold gap-flow conditions. For the three remaining surface sites located farther downwind of the CRG, the occurrence of freezing rain is not linked substantively to the depth of the gap flow. The number 

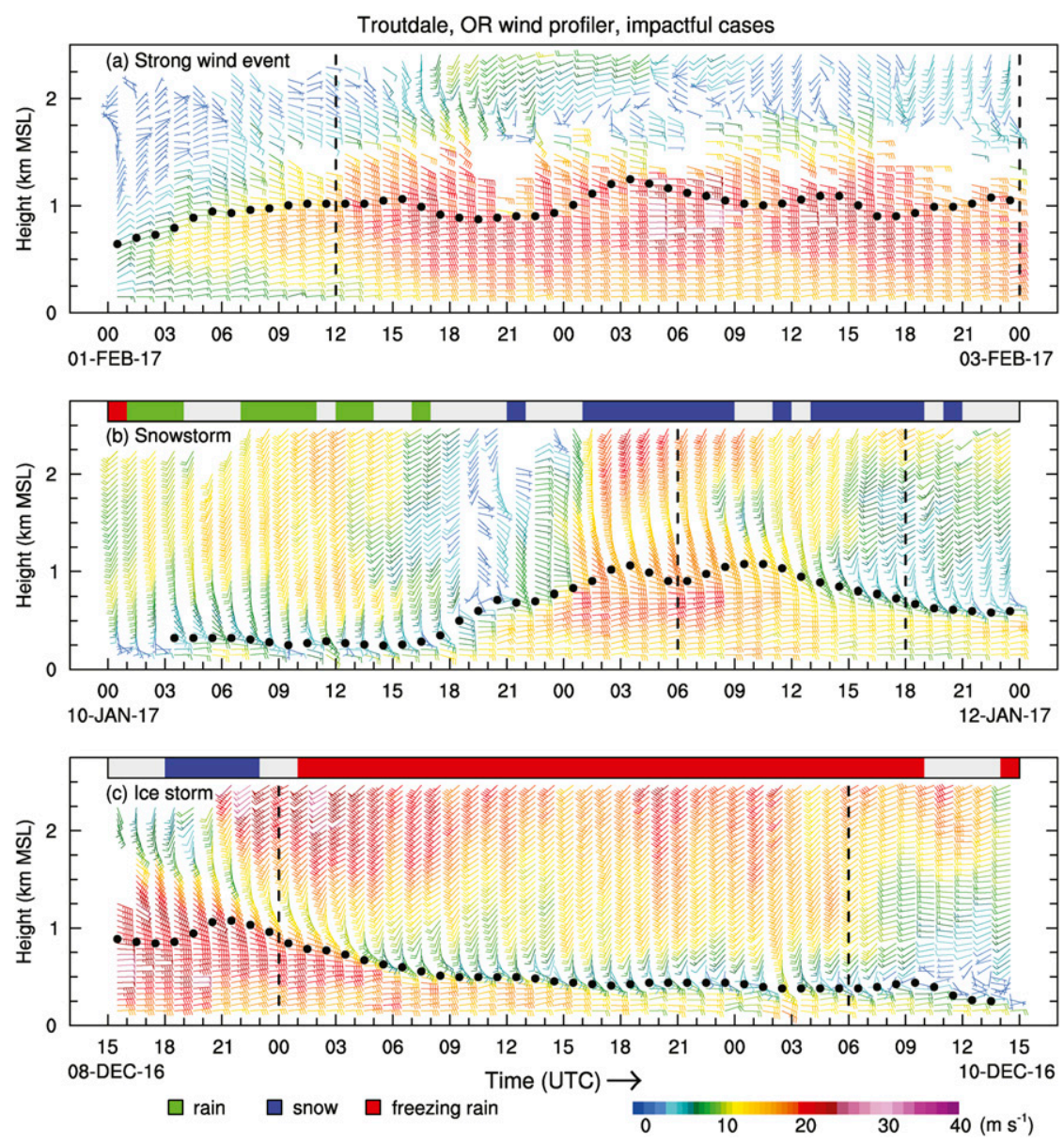

FIG. 13. Time-height sections of impactful gap-flow events measured by the $915-\mathrm{MHz}$ wind profiler at TDE: (a) strong wind event, between 0000 UTC 1 Feb and 0000 UTC 3 Feb 2017; (b) snowstorm, between 0000 UTC 10 Jan and 0000 UTC 12 Jan 2017; and (c) ice storm, between 1500 UTC 8 Dec and 1500 UTC 10 Dec 2016. Wind flags and barbs, color-coding (color bar at bottom), and black dots are as in Fig. 2a. The horizontal color bars in (b) and (c) show the predominant hourly precipitation type (color key at bottom). The pair of vertical black dashed lines in each panel represent the temporal endpoints of the 6-h gridded dataset times used to construct the corresponding case-composite analyses in Fig. 14.

of snow reports is directly proportional to the depth of the gap flow, and the deepest gap-flow conditions yield, by far, the greatest number of such reports. This scenario is consistent with the notion that deep, cold gap flow creates conditions whereby the atmospheric column is less likely to possess above-freezing temperatures to melt snow. Last, the deepest quartile produces regionally homogenous snow occurrences, whereas the shallowest two quartiles yield a decrease in freezing-rain occurrences with increasing distance from the CRG.

The bold column-aligned numerical values in Fig. 12a are the fractional occurrences of hourly maximum surface wind gusts exceeding $7.2 \mathrm{~m} \mathrm{~s}^{-1}$ at the five surface sites when gap-jet easterly wind speeds at TDE exceed the top-quartile value of $16.8 \mathrm{~m} \mathrm{~s}^{-1}$. For these strong gap-jet conditions, roughly half the surface wind gust occurrences at TDE are observed in the two deepest gap-depth quartiles, with much smaller fractional occurrences in shallow gap-flow conditions. At PDX, HIO, and UAO, large fractional occurrences of gusty surface winds for strong gap-jet conditions (i.e., 0.78 to 0.85 ) far exceed that at TDE in the deepest gap-depth quartile. Hence, strong gap-jet flow at TDE is a more robust indicator of gusty surface winds across the Portland area than at the mouth of the gorge at TDE, especially when the gap flow is deep. We also explore the impact of the top quartile of hourly surface easterly wind speeds at TDE (i.e., $\geq 10.3 \mathrm{~m} \mathrm{~s}^{-1}$ ) on the fractional occurrence of gustiness at the five Portland-area sites (regular-font column). For strong surface easterly flow at TDE with 
the deepest gap-flow conditions, the fractional occurrences of gusty winds (i.e., 0.32 to 0.54 ) decrease significantly at all five sites relative to those fractional values based on strong gap-jet conditions. Consequently, using gap-jet easterly wind speed instead of the surface-wind counterpart at TDE provides value-added information on wind impacts across the Portland area.

The bold (regular) numerical values in Fig. 12b represent the fractional occurrences of freezing rain and snow at the five surface sites when gap-jet (surface) easterly wind speeds at TDE exceed the top-quartile value of $16.8(10.3) \mathrm{m} \mathrm{s}^{-1}$. For the top two gap-flow depth quartiles, nearly all occurrences of freezing rain across the Portland area (0.93-1.00) are associated with strong gap-jet easterly flow, while fewer fractional occurrences of freezing rain (0.43-1.00) are tied to strong easterly flow at the surface. For the second shallowest gap-depth quartile, these fractional occurrences decrease for both of the easterly wind speed metrics, although they are still larger for the gap-jet speeds. The shallowest gap-depth quartile shows no useful linkage between easterly wind speed and the fractional occurrence of freezing rain. Snowfall across Portland is most prevalent in the deepest gap-depth quartile, so we focus on that quartile where strong gapjet speeds yield significant fractional occurrences of snow (0.65-0.78). These fractional occurrences are smaller (0.40-0.49) for easterly surface wind speeds. As with surface wind gusts across the Portland area, using gapjet easterly wind speed instead of the surface-wind counterpart at TDE provides value-added information on winter-type precipitation.

Examples of the most impactful cases related to strong wind, snow, and freezing rain are highlighted in bold in Table 2 and are summarized in Table 4 in terms of downstream weather impacts, synoptic characteristics, and gap-jet-strength and gap-flow-depth relationships previously established in this section. The vertical and temporal evolution of each case is depicted by timeheight sections of wind profiles and gap-flow depth in Fig. 13, and key synoptic-scale characteristics are represented by case composites of 500-hPa geopotential height and 1000-hPa temperature in Fig. 14. Consistent with the composite-impacts results in Fig. 12, both the strong-wind and snow events possess gap-jet strength and gap-flow depth that are in the top quartile, whereas for freezing rain the gap-jet strength (gap-flow depth) comprise the middle-two (lowest-two) quartiles. In addition, the synoptic-scale controls for these three events are consistent with the results of this study and Sharp and Mass (2004). Specifically, the strong-wind case mirrors the composite stratifications for gap-jet strength and gap-flow depth, while both the snowstorm and ice storm cases are similar in character to the precipitationtype composites in Sharp and Mass.

\section{Summary and conclusions}

This study utilized unique, temporally continuous, vertical data collected by three wind profilers during two cool seasons between October 2015 and April 2017 to provide a comprehensive observational characterization of the composite vertical and temporal structure of westward-directed gap flows along the Columbia River corridor from the interior basin to the coast, with an emphasis on the exit region of the gorge at TDE. During this period, the TDE wind profiler observed 92 gap-flow cases (44 in year 1 and 48 in year 2) spanning 3546h.

Vertical-composite analysis provided quantitative depiction of gap flows through the CRG using the methodology described by Neiman et al. (2018) to detect structural characteristics such as gap flow jet speed and depth. The mean gap-jet speed at TDE was $12 \mathrm{~m} \mathrm{~s}^{-1}$, and the mean altitude of the jet was observed at $363 \mathrm{~m}$ MSL. A mean gap-flow depth of $570 \mathrm{~m}$ MSL was situated below the top of the inner gorge, while the deepest gapflow depth was $1087 \mathrm{~m}$ MSL-entirely within the gorge's outer-wall rim. The mean gap-flow depth was deepest in the cold-air source region east of the gorge and decreased westward to the coast $(1 \mathrm{~km}$ at WCO, $0.61 \mathrm{~km}$ at TDE, and $<0.1 \mathrm{~km}$ at AST), which confirms model simulations by Sharp (2002). The gap-flow cases were stratified by strength and depth at TDE. Strong gap-flow events were, on average, longer lived, deeper, and capped by stronger vertical shear than their weak counterparts. Companion CFSv2 reanalysis composites revealed that strong events were governed by a cold interior anticyclone whereas the weak events were dominated by an offshore cyclone. The deep gap-flow events were, on average, longer lived, stronger, and with weaker capping vertical shear than their shallow counterparts. Deep events were associated with geostrophic offshore flow in the lower troposphere, which suggests that such events represented a combination of gap-flow and synoptic forcing.

Temporal-composite analysis provided physical insight into the evolution of CRG gap flows, which comprised five dominant phases. First, prior to gap-flow initiation, a cold pool forms in the Columbia basin through persistent longwave radiative cooling and/or the advection of an arctic air mass. Gap flow ensues in the CRG as the interior cold pool intensifies, and as negative SLP tendencies associated with an approaching offshore synoptic-scale frontal wave are first observed west of the CRG. The second phase represents mature gap flow, where the deepest gap flow is maintained 


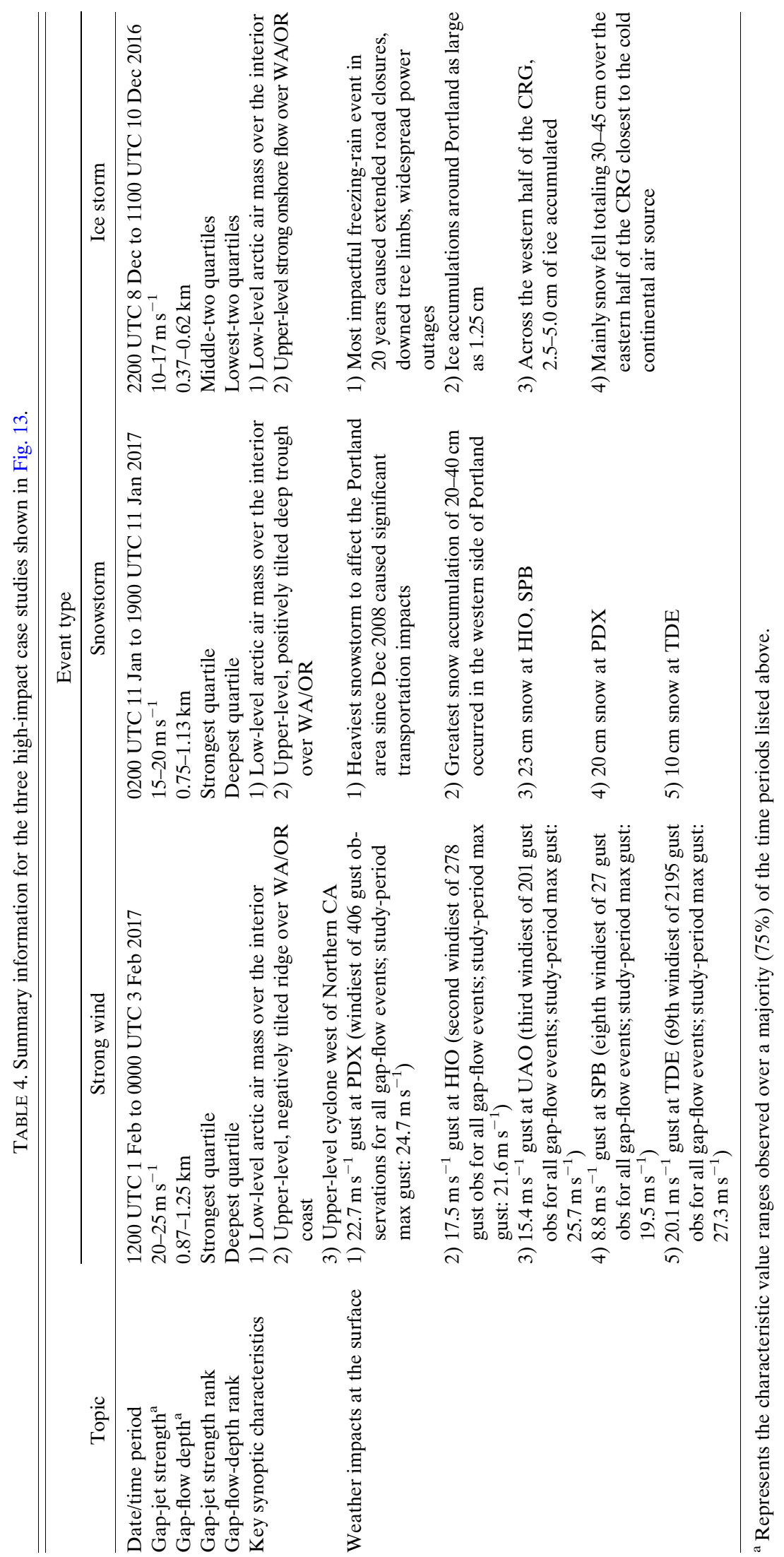



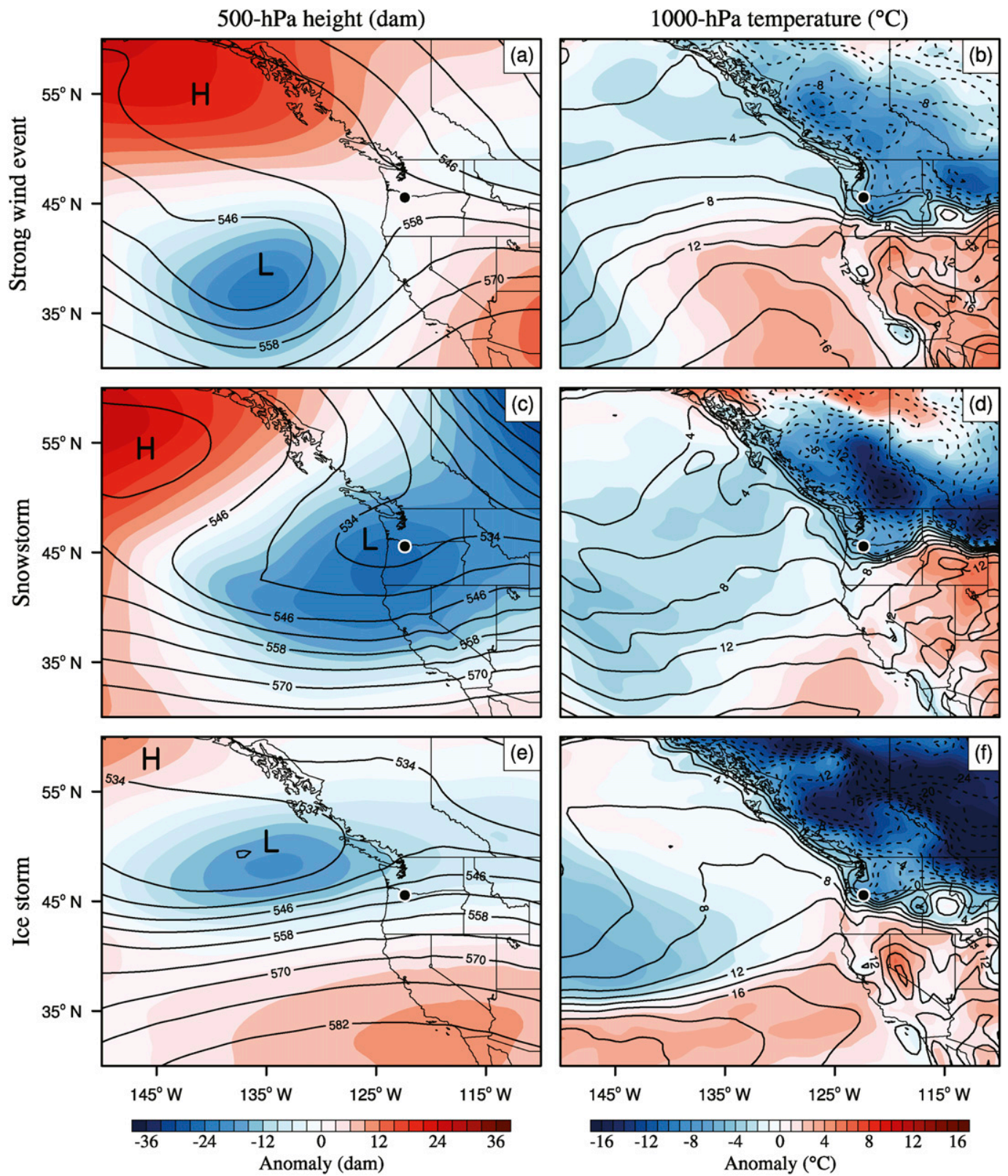

FIG. 14. Case-composite mean and anomaly analyses (solid and color-filled contours, respectively) for (left) 500-hPa height (dam) and (right) 1000-hPa temperature $\left({ }^{\circ} \mathrm{C}\right)$ derived from NOAA's Climate Forecast System 6-h gridded datasets. (a),(b) Strong wind event, composed of seven 6-h gridded dataset times between 1200 UTC 1 Feb and 0000 UTC 3 Feb 2017. (c),(d) Snowstorm event, composed of three 6-h times between 0600 and 1800 UTC 11 Jan 2017. (e),(f) Ice storm event, composed of six 6-h times between 0000 UTC 9 Dec and 0600 UTC 10 Dec 2016. The anomaly reference period is 1981-2010. The location of TDE is shown with a black dot.

during the first half of the event and the strongest gap-jet speeds occur at midevent. These flow enhancements result from constructive contributions from both frontalwave and cold-pool forcing, as SLP falls dominate west of the CRG and surface temperatures reach their minimum east of the CRG. During the third phase, gap-flow depth and gap-jet speed decrease during the latter half of the event, as frontal-wave forcing dominates and cold-pool forcing wanes. Decreasing gap-flow depth coincides with a synoptically driven wind direction shift and subsequent increase in cross-barrier southwesterly flow aloft, which can increase vertical-shear instability and Cascade-leeward effects (e.g., flow acceleration, wave activity, and downslope warming) aloft. The resulting 
top-down turbulent mixing warms temperatures within the gap flow at a greater rate to the east than west of the CRG, thus reducing the SLP gradient and flow within the CRG. At the gap exit, snowfall occurs during phases 2 and 3, while freezing rain is confined to phase 3 when the gap flow becomes shallow and cumulative precipitation is maximized prior to cold-frontal passage. In the fourth phase, shallow and relatively weak gap-flow at the western end of the CRG ceases, as the combination of intensifying vertical-shear instability and synoptic-pressure rises occur with cold-frontal passage. During the fifth phase, cold-frontal passage occurs above the cold pool east of the CRG, where the ensuing cold advection aloft can weaken the capping temperature inversion and allow boundary layer mixing to further erode the interior cold pool. The initiation and cessation of the observed gap flows exhibited modest diurnal behavior with the begin (end) times occurring most often during the local evening (morning) hours. We attributed these behaviors to radiational cooling at night and convective turbulent mixing during the day. During the cool season, gap flow was most persistent in January, when longer-duration events associated with an anomalously amplified synoptic-scale pattern were maintained by strong radiational cooling and arctic outbreaks over the interior and warm advection off the coast.

Observations of gap-flow depth and gap-jet strength at the CRG exit served as useful diagnostics for assessing potentially impactful weather, such as wind gusts and winter precipitation, downstream over the Portland metropolitan area. At PDX, HIO, and UAO, where gap-flow spreads horizontally and collapses vertically, gusty surface winds $\geq 7.2 \mathrm{~m} \mathrm{~s}^{-1}$ were associated primarily with the deepest quartile of gap flows at TDE. For the two deepest quartiles, strong gap-jet speed at TDE was also a useful indicator of gusty surface winds across the Portland area and provided value-added information relative to using surface-wind observations at TDE. At TDE and PDX, the number of freezing rain hours mostly increased with decreasing gap-flow depth, while, at the three remaining sites located farther downstream of the CRG, the occurrence of freezing rain was not linked substantively to gap-flow depth. The number of snow reports was directly proportional to the depth of the gap flow. The deepest quartile produced regionally homogenous snow occurrences, whereas the shallowest two quartiles yielded a decrease in freezing-rain occurrences with increasing distance from the CRG. As with surface wind gusts across the Portland area, using gapjet easterly wind speed instead of the surface-wind counterpart at TDE provided value-added information on winter-type precipitation.
The high-resolution spatiotemporal characteristics of the wind profiler data can also be utilized in numericalmodel verification studies to improve forecast performance and process understanding. While a detailed forecast-verification assessment is beyond the scope of this study, a basic assessment was conducted to demonstrate the use of derived observational metrics, namely gap-jet strength and gap-flow depth, as performance measures of the NWS 3-km High-Resolution Rapid Refresh (HRRR; Benjamin et al. 2016) operational forecasts (Fig. 15). The mean difference between observed and forecast gap-jet speed (Fig. 15a) and gapflow depth (Fig. 15b) show that the forecasts are biased weak and low for all verification times. In particular, the fastest-quartile jets and the deepest-quartile depths are associated with the largest mean errors, which, as demonstrated in section 4 , can have significant ramifications on surface wind gust and freezing-precipitation impacts over the Portland metropolitan area. The identification of such errors can help guide future studies to reveal model deficiencies responsible for those errors. For example, the accurate HRRR-forecast results for the shallowest gap-flows in the gap-exit region $(\leq 0.47 \mathrm{~km}$ in Fig. 15b) differ from the case-oriented, model-simulation findings by Sharp (2002), where a 4-km horizontal grid resulted in an elevated gap that prevented cold air from flowing through the CRG. Similar verification analysis could offer evidence-based guidance for these types of model sensitivity studies to more accurately identify the optimum grid resolution for the CRG and also to document the gap-flow-depth-detection limitations of other operational forecast models using coarser grids. In contrast, the degraded forecast performance of the deepest gap flows $(\geq 0.77 \mathrm{~km}$ in Fig. 15b), which should be less sensitive to HRRR misrepresentations in terrain than the shallowest gap-flow-depth cases, suggests that the modeled depth and evolution of the interior cold pool warrants further detailed study.

The observation-based results from this two cool-season study confirm that radar wind profilers provide reliably and continuously detailed wind measurements in all weather conditions that are necessary for studying gap flows. Backscatter from both clear-air below $\sim 1.5 \mathrm{~km}$ MSL and frequently occurring precipitation generated above the gap flow in the CRG produced comprehensive timeheight data coverage that is unlikely to be matched by other common remote sensing technologies (e.g., lidar and sodar) due to signal attenuation by precipitation. However, because radar clear-air backscatter is dependent on turbulence structures in moisture, decreased performance should be anticipated when attempting to study drier gap flows in higher-elevation terrain or more arid climates using wind profilers. 
Forecast Verification (HRRR minus observation)

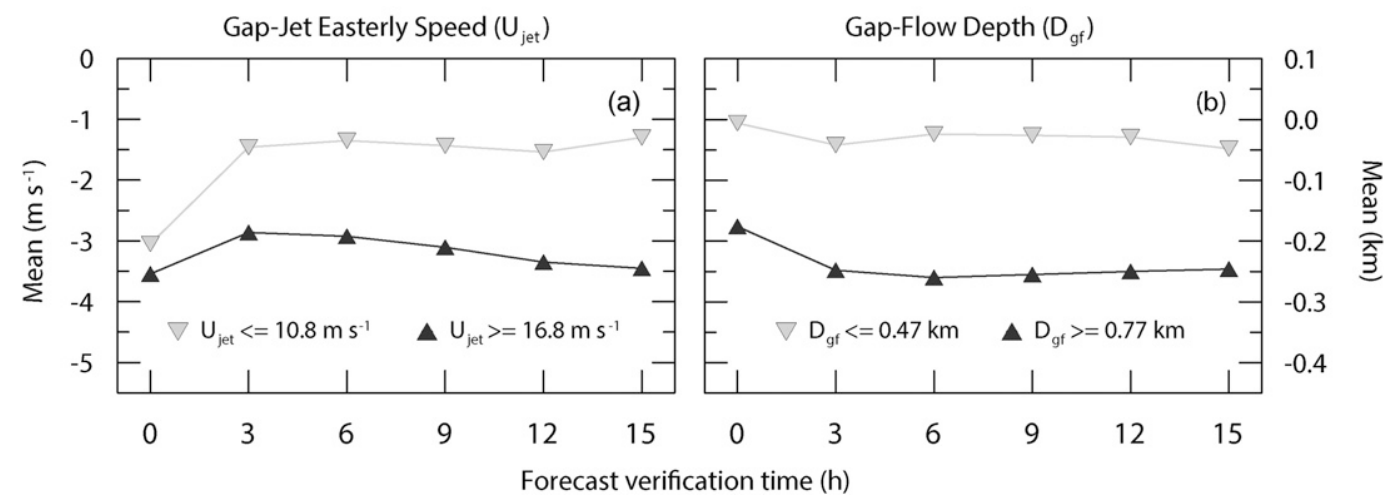

FIG. 15. Forecast verification statistics based on differences between hourly TDE wind profiler observations and HRRR (i.e., HRRR minus observations) for the observed top and bottom quartiles (black and gray triangles, respectively) of (a) mean gap-jet easterly wind speed $\left(\mathrm{m} \mathrm{s}^{-1}\right.$ ) and (b) mean gap-flow depth (km MSL). The top-and bottom-quartile thresholds for gap-jet speed are 16.8 and $10.8 \mathrm{~m} \mathrm{~s}^{-1}$, respectively, and for gap-flow depth are 0.77 and $0.47 \mathrm{~km} \mathrm{MSL}$, respectively. Forecast verification times are at 3-h intervals, from the initialization through $15 \mathrm{~h}$. The observed and modeled hourly gap-jet speed and gap-flow depth are determined using the automated algorithm in Neiman et al. (2018).

Despite the comprehensive kinematic depiction provided by the radar wind profiler in this study, significant deficiencies remain in acquiring and resolving the vertical temperature structure. The height coverage of the RASS measurements at TDE was $<0.5 \mathrm{~km}$ MSL during the windiest gap flows, with a maximum height coverage of $1.5 \mathrm{~km}$ MSL during the weakest flow regimes. The strongest and deepest wind composite analyses at WCO (Figs. 3, 4) suggest that the cold-air reservoir located east of the CRG is at least as deep as $1.25 \mathrm{~km} \mathrm{MSL}$. As such, further observational and modeling-verification studies of the interior cold pool depth and evolution will require improvements in the vertical temperature measurement. Furthermore, the physical processes responsible for the rapid changes in gap-flow depth and gap-jet speed along the CRG may be associated with thermodynamic changes well above the gap-flow (e.g., related to mountain wave activity), and may require vertical temperature profiling up to midtropospheric levels (Mayr et al. 2007). In an attempt to address this measurement shortcoming, ESRL is activity pursuing alternative RASS sampling methods, including the use of acoustic sources at multiple radii from the radar antenna, to improve height coverage during windy periods. Experimentation is also underway to augment groundbased microwave-radiometer calibrations with realtime, low-level RASS temperature profiles, which may offer the greatest potential for detailed temperature profiling up to the midtropospheric altitudes.

Last, the continuous spatiotemporal quality of the results in this study verify that the objective-analysis methodologies of Neiman et al. (2018) are likely applicable to other observational and modeling investigations of gap flow, with comparable data resolutions (i.e., a minimum of hourly vertical profiles with $60-\mathrm{m}$ resolution). In addition, there is potential to use additional metrics for the future study of gap flows. For example, if temperature-profiling improvements are realized, the bulk vertical gradients of horizontal velocity and temperature can be used (via the Bulk Richardson Number) to estimate the presence and magnitude of turbulence at the top of and within gap flows. Such data could be used to explore whether turbulent mixing at the top of gap flows plays a significant role in their cessation, which could be corroborated further by enhanced spectral-width measurements in the radar Doppler spectrum during clear-air backscatter (e.g., White et al. 1999; McCaffrey et al. 2017). Also, during clear-air return, there is potential to detect vertical velocity associated with mesoscale processes, such as mountain waves, that may contribute to the rapid along-gap modulation of gap-flow depth that has been observed in this and prior studies.

Acknowledgments. The authors thank the engineering staff at NOAA/ESRL for installing and maintaining the research observing equipment. Tyree Wilde at the PDX NWS Weather Forecast Office provided weather-impacts information related to the snowstorm and ice-storm case studies. We are grateful for comments by three anonymous reviewers and Drs. James Wilczak and Michael Alexander of NOAA/ESRL. Their input improved our manuscript. The collection of observations used in this study was supported by NOAA's Atmospheric 
Science for Renewable Energy Program and by the U.S. Department of Energy's Office of Energy Efficiency and Renewable Energy under Interagency Agreement DE-EE0007605.

\section{REFERENCES}

Benjamin, S. G., and Coauthors, 2016: A North American hourly assimilation and model forecast cycle: The Rapid Refresh. Mon. Wea. Rev., 144, 1669-1694, https://doi.org/10.1175/ MWR-D-15-0242.1.

Bond, N. A., C. F. Dierking, and J. D. Doyle, 2006: Research aircraft and wind profiler observations in Gastineau channel during a Taku wind event. Wea. Forecasting, 21, 489-501, https://doi.org/10.1175/WAF932.1.

Carter, D. A., K. S. Gage, W. L. Ecklund, W. M. Angevine, P. E. Johnston, A. C. Riddle, J. S. Wilson, and C. R. Williams, 1995: Developments in UHF lower tropospheric wind profiling at NOAA's Aeronomy Laboratory. Radio Sci., 30, 977-1001, https://doi.org/10.1029/95RS00649.

Colle, B. A., and C. F. Mass, 2000: High-resolution observations and numerical simulations of easterly gap flow through the Strait of Juan de Fuca on 9-10 December 1995. Mon. Wea. Rev., 128, 2398-2422, https://doi.org/10.1175/1520-0493(2000) 128<2398:HROANS > 2.0.CO;2.

Finn, D., and Coauthors, 2016: Evidence for gap flows in the Birch Creek Valley, Idaho. J. Atmos. Sci., 73, 4873-4894, https:// doi.org/10.1175/JAS-D-16-0052.1.

Gaberšek, S., and D. Durran, 2006: Gap flows through idealized topography. Part II: Effects of rotation and surface friction. J. Atmos. Sci., 63, 2720-2739, https://doi.org/10.1175/ JAS3786.1.

Green, M. C., J. Xu, and N. Adhikari, 2008: Transport of atmospheric aerosol by gap winds in the Columbia River Gorge. J. Appl. Meteor. Climatol., 47, 15-26, https://doi.org/10.1175/ 2007JAMC1561.1.

Martner, B. E., and Coauthors, 1993: An evaluation of wind profiler, RASS, and microwave radiometer performance. Bull. Amer. Meteor. Soc., 74, 599-613, https://doi.org/10.1175/ 1520-0477(1993)074<0599:AEOWPR > 2.0.CO;2.

Mayr, G. J., and Coauthors, 2004: Gap flow measurements during the Mesoscale Alpine Programme. Meteor. Atmos. Phys., 86, 99-119, https://doi.org/10.1007/s00703-003-0022-2.

— Alpine programme. Quart. J. Roy. Meteor. Soc., 133, 881-896, https://doi.org/10.1002/qj.66.

McCaffrey, K., L. Bianco, and J. M. Wilczak, 2017: Improved observations of turbulence dissipation rates from wind profiling radars. Atmos. Meas. Tech., 10, 2595-2611, https://doi.org/ 10.5194/amt-10-2595-2017.
McDonald, A. J., T. K. Carey-Smith, D. A. Hooper, G. J. Fraser, and B. P. Lublow, 2004: The effect of precipitation on windprofiler clear air returns. Ann. Geophys., 22, 3959-3970, https://doi.org/10.5194/angeo-22-3959-2004.

Neiman, P. J., F. M. Ralph, A. B. White, D. D. Parrish, J. S. Holloway, and D. L. Bartels, 2006: A multiwinter analysis of channeled flow through a prominent gap along the northern California Coast during CALJET and PACJET. Mon. Wea. Rev., 134, 1815-1841, https://doi.org/10.1175/MWR3148.1.

— D. J. Gottas, A. B. White, W. R. Schneider, and D. Bright, 2018: A real-time online data product that automatically detects easterly gap flow events and precipitation type in the Columbia River Gorge. J. Atmos. Oceanic Technol., 35, 2037-2052, https://doi.org/10.1175/JTECH-D-18-0088.1.

Saha, S., and Coauthors, 2010: The NCEP Climate Forecast System Reanalysis. Bull. Amer. Meteor. Soc., 91, 1015-1057, https://doi.org/10.1175/2010BAMS3001.1.

_ , and Coauthors, 2014: The NCEP Climate Forecast System version 2. J. Climate, 27, 2185-2208, https://doi.org/10.1175/ JCLI-D-12-00823.1.

Sharp, J. M., 2002: Columbia Gorge gap flow: Insights from observational analysis and ultra-high-resolution simulation. Bull. Amer. Meteor. Soc., 83, 1757-1762, https://doi.org/10.1175/ BAMS-83-12-1757.

_ 2005: The structure and dynamics of Columbia Gorge gap flow revealed by high-resolution numerical modeling. Ph.D. thesis, University of Washington, $190 \mathrm{pp}$.

__ , and C. F. Mass, 2004: Columbia Gorge gap winds: Their climatological influence and synoptic evolution. Wea. Forecasting, 19, 970-992, https://doi.org/10.1175/826.1.

White, A. B., R. J. Lataitis, and R. S. Lawrence, 1999: Space and time filtering of remotely sensed velocity turbulence. J. Atmos. Oceanic Technol., 16, 1967-1972, https://doi.org/10.1175/15200426(1999)016<1967:SATFOR $>2.0 . \mathrm{CO} ; 2$.

_ serving network for monitoring extreme weather events. J. Atmos. Oceanic Technol., 30, 1585-1603, https://doi.org/ 10.1175/JTECH-D-12-00217.1.

Whiteman, C. D., S. Zhong, W. J. Shaw, J. M. Hubbe, and X. Bian, 2001: Cold pools in the Columbia Basin. Wea. Forecasting, 16, 432-447, https://doi.org/10.1175/1520-0434(2001)016<0432: CPITCB $>2.0$.CO;2.

Wilczak, J. M., and Coauthors, 2019: The second Wind Forecast Improvement Project (WFIP2): Observational field campaign. Bull. Amer. Meteor. Soc., 100, 1701-1723, https://doi.org/ 10.1175/BAMS-D-18-0035.1.

Zhong, S., C. D. Whiteman, X. Bian, W. J. Shaw, and J. M. Hubbe, 2001: Meteorological processes affecting the evolution of a wintertime cold air pool in the Columbia Basin. Mon. Wea. Rev., 129, 2600-2613, https://doi.org/10.1175/1520-0493(2001) $129<2600$ :MPATEO > 2.0.CO;2. 